\title{
SOEP
}

SOEPpapers

SOEPpapers
on Multidisciplinary Panel Data Research

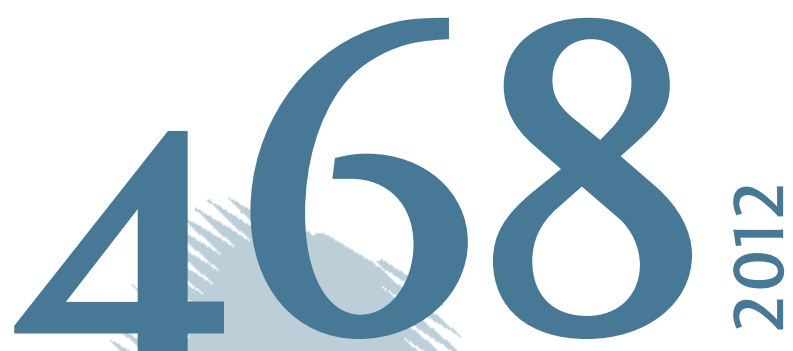

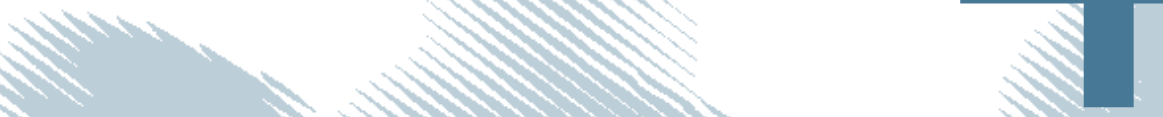

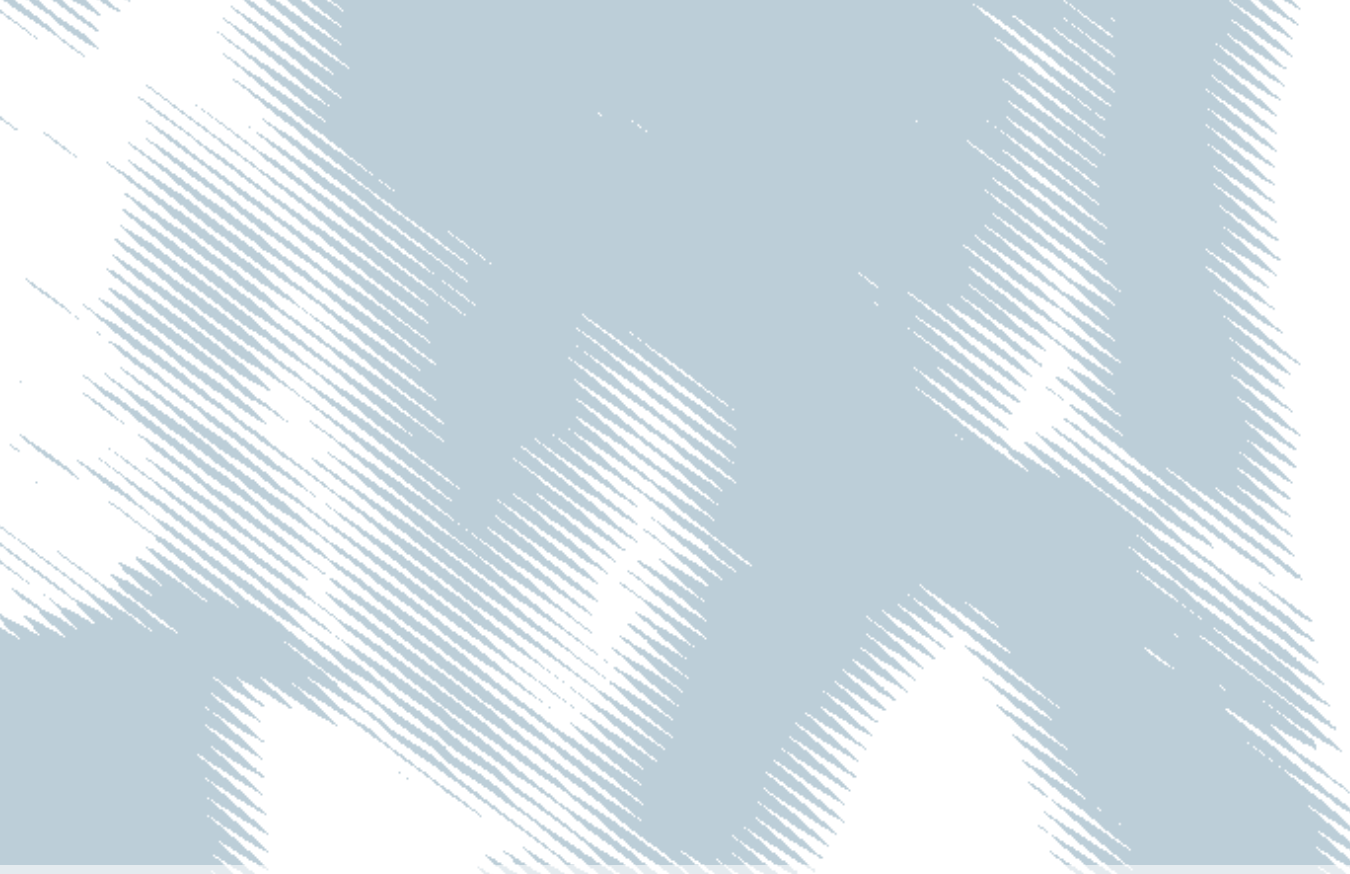

\section{The Great Happiness Moderation}

Andrew E. Clark, Sarah Flèche, Claudia Senik 


\section{SOEPpapers on Multidisciplinary Panel Data Research}

at DIW Berlin

This series presents research findings based either directly on data from the German SocioEconomic Panel Study (SOEP) or using SOEP data as part of an internationally comparable data set (e.g. CNEF, ECHP, LIS, LWS, CHER/PACO). SOEP is a truly multidisciplinary household panel study covering a wide range of social and behavioral sciences: economics, sociology, psychology, survey methodology, econometrics and applied statistics, educational science, political science, public health, behavioral genetics, demography, geography, and sport science.

The decision to publish a submission in SOEPpapers is made by a board of editors chosen by the DIW Berlin to represent the wide range of disciplines covered by SOEP. There is no external referee process and papers are either accepted or rejected without revision. Papers appear in this series as works in progress and may also appear elsewhere. They often represent preliminary studies and are circulated to encourage discussion. Citation of such a paper should account for its provisional character. A revised version may be requested from the author directly.

Any opinions expressed in this series are those of the author(s) and not those of DIW Berlin. Research disseminated by DIW Berlin may include views on public policy issues, but the institute itself takes no institutional policy positions.

The SOEPpapers are available at

http://www.diw.de/soeppapers

\section{Editors:}

Jürgen Schupp (Sociology, Vice Dean DIW Graduate Center)

Gert G. Wagner (Social Sciences)

Conchita D'Ambrosio (Public Economics)

Denis Gerstorf (Psychology, DIW Research Professor)

Elke Holst (Gender Studies)

Frauke Kreuter (Survey Methodology, DIW Research Professor)

Martin Kroh (Political Science and Survey Methodology)

Frieder R. Lang (Psychology, DIW Research Professor)

Henning Lohmann (Sociology, DIW Research Professor)

Jörg-Peter Schräpler (Survey Methodology, DIW Research Professor)

Thomas Siedler (Empirical Economics)

C. Katharina Spieß (Empirical Economics and Educational Science)

ISSN: 1864-6689 (online)

German Socio-Economic Panel Study (SOEP)

DIW Berlin

Mohrenstrasse 58

10117 Berlin, Germany

Contact: Uta Rahmann | soeppapers@diw.de 


\title{
The Great Happiness Moderation*
}

\author{
Andrew E. Clark, Sarah Flèche and Claudia Senik (Paris School of Economics)
}

July 9th 2012

\begin{abstract}
This paper shows that within-country happiness inequality has fallen in the majority of countries that have experienced positive income growth over the last forty years, in particular in developed countries. This new stylized fact comes as an addition to the Easterlin paradox, which states that the time trend in average happiness is flat during episodes of long-run income growth. This mean-preserving declining spread in happiness comes about via falls in both the share of individuals who declare low and high levels of happiness. Rising income inequality moderates the fall in happiness inequality, and may even reverse it after some point, for example in the US starting in the 1990s. Hence, if raising the income of all does not raise the happiness of all, it will at least harmonize the happiness of all, providing that income inequality does not grow too much. Behind the veil of ignorance, lower happiness inequality would certainly be considered as attractive by risk-averse individuals.
\end{abstract}

Keywords: Happiness, inequality, economic growth, development, Easterlin paradox.

JEL codes: D31, D6, I3, O15

\footnotetext{
* We thank CEPREMAP for financial support. We are grateful to participants in the PSE-CEPREMAP -DIMeco Conference on "Happiness and Economic Growth", Paris, March $9^{\text {th }}$ 2012, and in particular Paul Seabright, and participants at the FUNDP Namur Economics Seminar, May $29^{\text {th }}$ 2012. The BHPS data were made available through the ESRC Data Archive. The data were originally collected by the ESRC Research Centre on Micro-social Change at the University of Essex. The German data used in this paper were made available by the German Socio-Economic Panel Study (SOEP) at the German Institute for Economic Research (DIW), Berlin: see Wagner et al. (2007). The Household, Income and Labour Dynamics in Australia (HILDA) Survey was initiated and is funded by the Australian Government Department of Families, Housing, Community Services and Indigenous Affairs (FaHCSIA), and is managed by the Melbourne Institute of Applied Economic and Social Research (Melbourne Institute). Neither the original collectors of the data nor the Archives bear any responsibility for the analyses or interpretations presented here.
} 


\section{Introduction}

What should the populations of developing countries expect from income growth and development? Easterlin and various co-authors have shown that, paradoxically, average happiness does not increase over the long run, during episodes of sustained growth. But what about the distribution of happiness? Can individuals at least count on the social harmonization of well-being?

The current paper does not address changes in average happiness, and takes for granted the stylized fact that constitutes the Easterlin paradox (the flatness of happiness curves over the long run). Instead, and in contrast to most of the related literature, it appeals to the individual dimension of many of the available datasets to analyze the evolution of the distribution of happiness over time. Whereas Easterlin considered the first moment of happiness over time, we here want to look at the second moment.

From a policy point of view, the distribution of happiness across individuals is an indicator of interest, although a purely utilitarian objective would only aim to maximize total happiness. First, for risk-averse agents, happiness inequality is a bad, and behind the veil of ignorance they would certainly choose a society where happiness is more evenly distributed. Second, what egalitarian policies ultimately try to harmonize is the welfare of their citizens, not just their incomes, where the latter is just a proxy for the former. De facto, a number of authors have questioned the relevance of income inequality as measure of social inequality: Veenhoven (2005b), for example, advocates the measurement of inequality in longevity and happiness instead of income. Non-egalitarian governments may also try to equalize happiness because of the risk of social tension and unrest resulting from inequality in well-being. In a political-economy framework, discontent theories (Tullock 1971, Gurr, 1996) hypothesize 
that the expected gains from (and hence the likelihood of) rebellion are approximated by the happiness gap between the most and the least well-off. Our first objective is thus to see whether development policies bring the promise of reduced happiness gaps in this sense. Note that the variation in happiness within countries is typically twice as high as that across countries. For instance, in the World Values Survey (1981 to 2008), the average standard deviation in life satisfaction (on a 10-point scale) in a cross-section is 2.14 , but only 1.01 across countries. Hence, reducing within-country inequality is a valid objective.

The second motivation for this research is to contribute to our understanding of the Easterlin paradox. There are a number of explanations of the stability of average happiness over time. The first points to the concavity of the happiness function in income, so that rising income inequality mechanically reduces the mean level of happiness (Stevenson and Wolfers, 2008a, 2010, 2011). There are also more "behavioral" hypotheses, proposed by Easterlin himself, among which the most prominent are social comparisons and adaptation. Finally, because happiness is rated on a bounded scale, there is potential "rescaling”, in that individuals change their interpretation of the steps of the happiness scale as their income increases. All of these hypotheses are potentially consistent with a flat average happiness profile over time; however, it is not clear that they can also explain the changing distribution of happiness over time.

We here examine countries that have experienced continuous income growth over an extended period of time, between 1970 and 2010, and whose happiness profile over time is flat. We show that there is an inverse relationship over time between GDP per capita and happiness inequality. This inverse relationship also holds in cross-section correlations: across the countries in the World Values Survey (1970-2008), greater income per capita is associated with smaller standard deviations in happiness. We also focus on developed countries for which we have long annual series on happiness from surveys: Australia (HILDA), Germany 
(SOEP), Great Britain (BHPS) and the United States (General Social Survey). These data confirm the fall in happiness variation over time (except in more recent years in the US). This mean-preserving declining spread of happiness comes about via a fall in both the share of individuals who declare low and a high happiness scores. To paraphrase Easterlin, our findings suggest that raising the incomes of all will not increase the happiness of all, but will reduce its variance, and hence the risk of extreme unhappiness.

This harmonization in well-being is not just a mirror of the evolution in income inequality in each country: on the contrary, income inequality has risen during the period under consideration. These two opposite forces seem to coexist up to a certain point. In the United States, when income inequality became too large, in the 1990s, it overcame the downward trend in happiness dispersion. In the meantime, over this period, happiness gaps between certain categories of the population (by gender, by marital status) tended to fall, as did withingroup happiness inequality in general.

With respect to the various theories proposed to explain the Easterlin paradox, we find that social comparisons and simple time-dependent adaptation do not suffice to account for happiness moderation. In order to do so, it is necessary to consider more subtle concepts of adaptation (à la Maslow for instance) or rescaling effects. The homogenizing influence of the public good externalities of modern growth may also play a role.

\section{Existing Literature}

Some existing work has previously noted a drop in happiness inequality in developed countries over the last decade. Veenhoven (2005b) found, in spite of increasing income inequality, falling happiness inequality in EU countries (surveyed in the EuroBarometer), between 1973 and 2001. He also noted that the dispersion in happiness is smaller in "modern 
nations" than in traditional countries. Other work has documented a decline in happiness inequality in the US and Germany from the 1970s to the 1990s, with a rebound in the 1990s. This includes Stevenson and Wolfers (2008b), Ovaska and Takashima (2010), Dutta and Foster (2011) and Becchetti et al. (2011).

Stevenson and Wolfers (2008b) and Dutta and Foster (2011) both appeal to data from the General Social Survey in order to consider the evolution in and decomposition of happiness inequality in the United States. The former analyze the evolution of happiness inequality between 1972 and 2006. They find a 21\% fall in happiness inequality from the 1970s to the 1990s, about one-third of which is reversed in the subsequent decade. They also decompose the evolution in happiness inequality, and show that the happiness gap between men and women has vanished and that two-thirds of the black-white happiness gap has disappeared. In parallel, education and age gaps widened between 1972 and 2006. Generally, within-group inequality declined substantially up to the 1990's, but grew thereafter. The parallel increase in income inequality is not reflected in happiness inequality. They suggest that "the real reason for today's lower level of happiness inequality is to be found in a pervasive decline in withingroup inequality experienced by even narrowly defined demographic groups” (Stevenson and Wolfers, 2008b, p.S34). The role of non-pecuniary factors in shaping the well-being distribution is underlined: these include the institutional and technological changes (e.g. antidiscrimination and affirmative action, divorce laws, and birth control) that have increased the autonomy and freedom of choice of individuals, and increased opportunities for minorities. Dutta and Foster (2011) focus on the methodological aspects of measuring changing inequality in happiness, which is an ordinal variable. They apply a median-centered approach developed in a former paper and decompose happiness inequality across gender, race and religion. Their findings are close to those of Stevenson and Wolfers, apart for their conclusion 
that "the progress made in the 1990s in reducing happiness inequality has been wiped out in the 2000s" (p.6).

Becchetti et al. (2011) decompose the trend in happiness inequality in Germany (both East and West), from 1991 to 2007, using the SOEP. They use RIF regressions ${ }^{1}$ and decompose the variance of happiness between two periods (1991-1993 and 2005-2007). One of their main findings is that of no change in the coefficients: the returns to the drivers of happiness inequality do not vary over time. They also find that income inequality is not the main source of happiness inequality. Finally, they suggest that the main determinant of happiness inequality is the variance within categories of education (within variance is lower in higher education, and the weight of the higher-educated has increased over time). The common finding in this literature is the great importance of within-category variance and the lack of a relationship between income inequality and happiness inequality.

Other papers have looked at changing happiness inequality across countries, instead of over time. Ovaska and Takashima (2010) run aggregate regressions of happiness inequality on socioeconomic controls and income distribution, as well as measures of economic and political freedom taken from the Fraser Institute and Freedom House. They identify income inequality, health inequality and the poor quality of institutions as the main correlates of happiness inequality within countries. Ott (2010) also maps institutions to happiness inequality across a set of 131 countries in 2006.

In this paper, we use data from the World Values Survey, the German panel (SOEP) although over a longer period than Becchetti et al. (2011), the American General Social Survey (GSS),

\footnotetext{
${ }^{1}$ Recentered Influence Function (RIF) regressions are a generalization of the Oaxaca-Blinder (1973) procedure to other distributional parameters beyond the mean. They allow the total change in happiness inequality to be split into the change in the distribution of happiness determinants (composition effects) and the change in the return to these determinants (coefficients). It can also detail the contribution of each determinant.
} 
the British Household Panel Survey (BHPS) and Australian HILDA. We analyze the evolution of happiness inequality, defined as the standard deviation of happiness over its mean. We find, as in previous work, that changing income inequality does not predict happiness inequality. We uncover a general fall in the spread of happiness in all of the countries under consideration, although in Germany and the US, this trend breaks in the 1990s. Although Becchetti et al. (2011) document a rise in happiness inequality in Germany between 1991 and 2007, we take a longer view and obtain a different picture, whereby happiness inequality fell sharply in the 1980s and then fluctuates around a flat trend in the 1990s.

The main interest of this paper is the distribution of happiness, not the distribution of income. A considerable number of papers have discussed the relationship between income inequality and happiness; most have discovered a negative association, although there is no consensus on the strength of this link (see Clark et al., 2008, and Senik, 2009, for surveys). Other papers in the happiness literature have documented the negative correlation between macroeconomic volatility and happiness over time (Wolfers, 2003; Di Tella et al., 2003). Finally, macroeconomists have underlined a "great moderation" in the volatility of the business cycle, starting in the 1980s (Stock and Watson, 2002; Gali and Gambetti, 2009). Although this is a different issue, macroeconomic volatility could be related to happiness inequality if income inequality is compounded by inequality in income volatility, i.e. if health, unemployment and retirement risks are concentrated in poorer households (as noted by Stevenson and Wolfers, 2008a). 


\section{Data and methods}

\section{II.1 A cardinal measure of happiness inequality}

We measure happiness inequality as the standard deviation in self-declared happiness by respondents in a certain country in a given year. In order to avoid any scale-dependence, we divide this by the mean value of happiness in the same country-year (the two measures are homogenous). ${ }^{2}$ Self-declared happiness is a choice on a given scale: equality pertains when all respondents choose the same answer. Flat distributions are more unequal that those with concentration towards the top; wide flat distributions are more unequal than narrower flat ones; and multi-modal distributions are more unequal than unimodal ones (see Kalmijn and Veenhoven, 2005). Standard deviation is consistent with these properties, as it captures the notion of inequality in the sense of dispersion.

Of course, calculating the standard deviation (and the mean) of happiness implies treating the variable as a continuous cardinal measure, with equidistant steps. This is incorrect, but common in the field (see Van Praag, 1991 and 2007, Ferrer-i-Carbonell and Frijters, 2004, and Van Praag and Ferrer-i-Carbonell, 2004 and 2006). Van Praag (1991) has shown that respondents translate ordinal responses into a numerical scale. They may do so in a different way, but there is no reason to expect this heterogeneity to be correlated with the error term in the regression (Frey and Stutzer, 2002). Vignettes (Beegle et al., 2011) have shown that this is not correlated with happiness determinants, nor with the residual of the regressions. It has also been shown that the bias introduced by the continuity assumption is small when the scale

\footnotetext{
${ }^{2}$ We can refer to the general discussion by Kalmijn and Veenhoven (2005) over the adequate measure of happiness inequality. The authors conclude to the superiority of the standard deviation. They point out that the Gini index of inequality is not appropriate for happiness. Indeed, the Gini measures the share of total income that is not distributed equally, but happiness is an intensity variable, not a capacity variable: it cannot be appropriated entirely by one person or distributed flexibly amongst individuals. The same is true of Theil's index of inequality. They also discuss the drawbacks of the interquartile range or the proportion outside the mode.
} 
contains a large number of categories or steps (Ferrer-i-Carbonell and Frijters, 2004), which is the case for all the datasets that we use, except the GSS (which contains only three).

Dutta and Foster (2011) criticize the treatment of ordinal happiness as cardinal as the level of inequality will depend on the chosen scale, and so will the ranking of various societies or groups in terms of happiness inequality. Deviations from the mean will not be orderpreserving because the mean itself is not order-preserving under scale change. They instead propose scale-independent concepts that capture the concentration of the distribution around the median, as well as a mean-based inequality measure, which is the difference between the means in the upper and lower halves of the population.

Note that our findings are exactly identical to those in Dutta and Foster, and more generally to the papers cited above, which use different dispersion measures. To be one the safe side, we also use the index of ordinal variation (IOV, see Berry and Mielke 1992), a measure of polarization designed for ordinal measures, which describes the distribution of the population over a number of predetermined ordered categories and takes a value of zero when all observations fall into one category, and one in the case of extreme polarization. In order not to duplicate the tables, we just note the similarity of the two measures (the standard deviation and the IOV) for each year in each database (see Section A2 in the Appendix).

\section{2 Data}

This paper uses the five waves of the World Values Survey (WVS, 1981-2008), ${ }^{3}$ covering 105 countries, including high-income, low-income and transition countries. We select the time series data that correspond to periods of positive income growth (60 countries). ${ }^{4}$ Happiness measures were mostly taken from the WVS and the European Values Survey, but

\footnotetext{
${ }^{3}$ These datasets are available at http://worldvaluessurvey.org.
} 
when happiness data was missing we include information from the ISSP and the 2002 Latinobarometer. We also analyze individual-country surveys, such as the British Household Panel Survey (BHPS, 1996-2008), the German Socio-Economic Panel (SOEP, 1984-2009), the American General Social Survey (GSS, 1972-2010) and the Household, Income and Labour Dynamics in Australia survey (HILDA, 2001-2009). All figures and tables are based on weighted samples.

The Happiness and Life Satisfaction questions were administered in the same format across all these surveys but with different response scales: 1-3 in the GSS, 1-10 in the WVS, 0-10 in the SOEP and the Australian HILDA, 1-7 in the BHPS. The wording of the Life satisfaction question in the WVS was "All things considered, how satisfied are you with your life as a whole these days?: 1 (dissatisfied)....10(very satisfied)". In the SOEP, it was "How satisfied are you with your life, all things considered?”: 0 (totally unsatisfied) ... 10 (totally satisfied). The BHPS survey asked “How dissatisfied or satisfied are you with your life overall?”: 1 (not satisfied at all) ... 7 (completely satisfied)". The wording of the Happiness question in the GSS was "Taken all together, how would you say things are these days - would you say that you are very happy, pretty happy, or not too happy?”. We do not need to harmonize these scales, as we consider the evolution of the variance of happiness over time within countries. The surveys cover representative samples of the population in participating countries, with an average sample size of ten to fifteen thousand respondents in each wave. As is common, we select people aged between 18 and 65 years old; we also drop observations corresponding to a declared income of below 500\$ per year.

We use the American General Social Survey because it is the only long-run survey containing a happiness or life satisfaction question in the United States. However, this data is not really

\footnotetext{
${ }^{4}$ For a number of countries, we only have observations at one point in time.
} 
suited to our purpose, as only three responses are possible (very happy, pretty happy, and not too happy), making the calculation of the variance problematic. However, as the evidence initially used to suggest the Easterlin paradox partly relied on American data, and because we would like to include data from the United States, we do report the results based on this data, although we consider them with some caution.

It is natural to try to relate the happiness spread to the distribution of household income within countries. Ideally, we would like to use net disposable income after tax and transfers, which is probably most closely related to (consumption and) well-being. A measure of annual net disposable combined income after receipt of public transfers (Government pensions and benefits) and deduction of taxes is indeed available in the German and Australian data. This is not the case in the BHPS, where household income is measured as the sum of labor income, non-labor income and pensions over all household members, in the previous year, but before taxes. Equally, the GSS contains a measure of "total family income”, i.e. all types of income from all sources, for all members of the household, before taxes, in the previous year.

Finally, we use measures of GDP per capita taken from Heston, Summers and Aten - the Penn World Table. We also use indicators, which are available in the World databank, such as social expenditures, rule of law, voice and accountability and control of corruption. ${ }^{5}$ Voice and accountability measures the extent to which citizens are able to participate in the selection of their government, as well as freedom of expression, freedom of association and free media. Rule of law describes the quality of contract enforcement, of the police and courts, as well as the likelihood of crime and violence. Control of corruption measures the extent to which public power is exercised for private gain.

\footnotetext{
${ }^{5}$ http://info.worldbank.org/governance/wgi/index.asp.
} 


\section{Income growth creates a mean-preserving spread in happiness}

Before we turn to the relationship between income and happiness inequality over time, we briefly look at their cross-section correlation, taking the last available year for each country in the World Values Survey. As noted in Veenhoven (2005a), Kalmijn and Veenhoven (2005) and Clark and Senik (2011), this cross-country analysis produces a striking result: richer countries have higher life satisfaction scores, but with lower standard deviations (Figure 1.A). The typical relationship implies that a doubling of GDP per capita is associated with a $10 \%$ reduction in the spread of happiness. ${ }^{6}$ A RIF regression ${ }^{7}$ of the standard deviation of happiness on the log of GDP per capita, controlling for demographic variables and year fixedeffects (Table 1.A) confirms this visual impression. This negative gradient is moreover somewhat steeper in richer countries (where GDP per capita is over \$8000) than in poorer countries, as illustrated in Figure 1.B.

\section{2 Time-series evidence from the World Values Survey}

We now turn to the intertemporal relationship between GDP per capita and happiness inequality, and start with the World Values Survey, from which we retain countries that are observed at least twice, at least five years apart, and which experience strictly positive GDP growth in all of the intervening years. Figure 2 illustrates the downward trend in the level of happiness spread over time in Western countries. Figures 3.A and 3.B show the change in the standard deviation in happiness over periods of at least five years of growth. Figure 3.A illustrates the relationship between the long-run first-differences in income per capita and

\footnotetext{
${ }^{6}$ Figure 1.A shows that the coefficient on log GDP per capita in a regression of the standard deviation over the mean is 0.049. As such, a doubling of GDP per capita changes the standard deviation by $0.049 * \ln (2) *$ mean happiness. This equals 0.23 , as the mean value of happiness in the WVS is in the range of 6.7, and represents a ten percent fall in the standard deviation as this latter is in the range of 2.3.

${ }^{7}$ See Firpo et al. (2009) for a presentation of this method.
} 
happiness inequality. Each point here refers to a country: the X-axis corresponds to the change in GDP per capita between the two extreme dates of the growth period and the Y-axis the change in the standard deviation in happiness over the same period. The relationship is clearly negative: happiness inequality falls as per capita GDP increases over (at least five years of) time: a 10\% increase in GDP per capita is estimated to reduce the standard deviation in happiness by 0.02 points, i.e. by about $1 \%$ of the typical standard deviation figure. ${ }^{8}$ Figure 3.B carries out the same analysis on the sub-sample of Western developed countries.

We run a RIF regression of the standard deviation of happiness on log GDP per capita, controlling for various demographic variables and country fixed-effects. The results confirm the negative correlation between GDP per capita and the normalized standard deviation in happiness over time in WVS countries (column 1 in Table 1.B). The estimated slope is similar to that from the regression line in Figure 3.A.

Contrary to the relationship between average income and average happiness considered by Easterlin, there is here no contradiction between the cross-section and time-series results regarding the negative correlation between average income and happiness inequality.

The World Values Survey shows that the fall in happiness inequality over time (at least five years) is sharper in Western developed countries than in other countries. As such, we now focus on developed countries and turn to country-specific survey information.

\section{III.3 Individual-country evidence}

Having considered the repeated cross-sections of the World Values Survey, which contain few points in time and relatively few observations per cross-section, we now turn to countryspecific surveys, which contain tens of thousands of observations each year, and are repeated

\footnotetext{
${ }^{8}$ It will be lower by $0.043 * \ln (1.1) *$ mean happiness.
} 
almost every year. Figures 4.A to 4.D show two series of graphs for Great Britain, Germany, the US and Australia. The first plots the change over time in average happiness, log GDP per capita and average log household income (as declared in the household surveys), while the second plots the standard deviation of happiness and GDP per capita.

The average log of individual income curve, which is calculated from the surveys, is below that of GDP per capita for two reasons: first, surveys typically miss out the top incomes in a country (Atkinson et al. 2011); second, average log income will be lower than log average income if the income distribution is left-skewed. The gap between the two figures rises with income inequality. The two variables are plotted on the same graph as one of the questions in the literature is whether individual self-declared happiness is a function of log income (see Section IV.1). The graphs clearly show that the change in average happiness is different from that of mean log income.

Figures 4.A - 4.D are similar. We first note the Easterlin paradox: average happiness is flat over time despite income growth (either the log of the mean or the mean of the log). Second, the standard deviation in happiness falls over time. The only exceptions are Germany, where the downward trend breaks in the 1990's, and the US where the trend starts to rise again post1990.

We can draw similar graphs for some of the developed countries in the World Values Survey which meet three requirements: periods of positive income growth, information on points in time that are at least ten years apart, and with a flat happiness trend. As shown in Figure 4.E, all of the countries that meet these criteria exhibit a downward trend in happiness inequality (France, Italy, Spain, the Netherlands, and Norway). 
We should here underline that the negative relationship between the standard deviation in happiness and income per capita cannot be attributed to stochastic dependency or scale dependency. The latter would imply that in richer countries, where average happiness is higher, the standard deviation in happiness would also be higher. The negative correlation between average happiness and happiness dispersion should thus be interpreted as revealing an "intrinsic dependency" rather than a statistical one (in the words of Kalmijn and Veenhoven, 2005). On the other hand, Kalmijn and Veenhoven underline that on a bounded scale, maximal inequality pertains when the average value is at the middle of the scale, so that the maximum standard deviation is smaller for higher levels of average happiness. However, the actual measures of standard deviation that we obtain (in the range of 1.5-2.5) are below their maximum possible values (of around 7).

\section{Disappearing extreme happiness}

To fit our two stylized facts (a constant happiness trend with falling standard deviation), we expect a growing concentration of happiness over time. Figures 5.A - 5.D indeed reveal that over time the percentage declaring either very low or very high happiness shrinks, whereas the percentage in the middle rises. This is illustrated in both the histograms of self-declared happiness in the first and the last year of each survey, and by the change over time in the percentage of respondents choosing high, average and low happiness scores. Both graphs reveal a distinct convergence to the mean over time in all of the countries under consideration.

We thus have three concomitant stylized facts for the recent period of growth, especially in developed Western countries: (1) a rise in average income per capita; (2) flat average happiness; and (3) falling happiness inequality. 


\section{4 The role of income inequality}

Falling happiness inequality might be thought of as surprising, given that our time period is one of well-known rising income inequality, starting in the 1980s (Dustmann et al. 2008; Atkinson et al. 2011). If individual happiness depends on income, we should expect happiness inequality to have mirrored income inequality.

Figures 6.A - 6.D show the changes in the standard deviation of income and happiness in each country: income inequality follows an upward trend in all of our countries (whereas happiness inequality does not). In most countries here, the inequality in income between quintiles has risen, with the average income of the upper quintile increasing much more than that of the lower quintiles. ${ }^{9}$ The income of the bottom quintile has largely stagnated. However, when we plot the trends in happiness in the different income quintiles by country over time, we find no divergence in the happiness of the different quintiles. In the United States and Germany, between-group inequality in happiness initially fell (until 1990) but then grew again in Germany, due to the fall in the happiness of the poorest quintile. In the United States, there is a more general increasing inequality starting in the 1990's. In all of these countries, the within-quintile dispersion falls dramatically over time, although again within-group inequality increases after 1990 for the bottom quintile in Germany and the US. The general picture is hence one of increasing income inequality, but which is not matched by rising happiness inequality.

Should we then conclude that the change in happiness inequality is totally independent of income, as suggested by Stevenson and Wolfers (2008b), Dutta and Foster (2011) and Becchetti et al. (2011)? We answer by running a RIF regression of the standard deviation of

\footnotetext{
${ }^{9}$ See also Layard et al. (2010) for the United States.
} 
happiness on log GDP per capita and mean log deviation (see Stevenson and Wolfers, 2010). Table 1.A shows that happiness inequality increases with the mean log deviation of income but falls with average income. This can be taken as evidence of two opposing forces, which could explain the rebound in happiness inequality at the end of the period in Germany and the US. From the estimated coefficients, the impact of $30 \%$ higher GDP per capita is counterbalanced by higher mean log deviation of 0.05 points, i.e. about $35 \%$ of its average value in the sample. ${ }^{10}$

Overall, the fall in happiness inequality over time is not driven by a parallel reduction in income inequality. ${ }^{11}$ On the contrary, income inequality has risen in all the countries here, which acts as a countervailing force. This force is however not powerful enough to overcome the process of happiness equality, except in the United States towards the end of the period.

\section{5 Decomposing happiness inequality into micro and macro factors}

While happiness equality over time is not driven (but rather counteracted) by income inequality, it could also reflect a composition effect, i.e. greater socio-demographic homogeneity in the population.

We here start with a visual depiction of the evolution of average happiness by sociodemographic groups, and of the dispersion of happiness by group. As shown in Appendix Section A.3, happiness gaps between groups increase by education (except in Australia) and fall by gender and marital status (before increasing in Germany and the US, after 1990). The evolution of the gaps by age group and employment status is quite different across countries.

\footnotetext{
${ }^{10}$ This should rise by $0.89 * \ln (1.3) / 4.264=0.05$. The mean log deviation in the sample is in the region of 0.14 .

11 This may be because the impact of income inequality on happiness inequality is channeled via consumption inequality. Changes in the latter have been the object of vivid debate amongst academics. In the US for instance, most authors find rising consumption inequality in the 1980s, although Krueger and Perri (2006) conclude the opposite, that consumption inequality
} 
However, a common trend is that happiness inequality falls over time in all countries within age, education, gender, marital status and employment status groups, although most of this fall within groups changes sign in the US and Germany after 1990. In sum, the general trend is that happiness dispersion within different demographic groups is declining, as uncovered by Stevenson and Wolfers (2008a) and Becchetti et al. (2011).

RIF estimates of the variance in happiness in each country illustrate how the composition of the population affects happiness inequality. However, Table 1.B shows that GDP per capita and income inequality continue to affect happiness inequality even when controlling for socio-demographic variables. As shown in Table 1.A, this also is true in the cross-section estimates (controlling for year fixed-effects).

Lower happiness inequality does not then reflect the evolving socio-demographic composition of the population, although the within-group and between-group happiness spreads have changed over time. Even holding socio-demographic composition constant, income growth is associated with lower happiness inequality.

\section{Interpretations}

We would like to explain the following three stylized facts over time: (1) rising average income per capita; (2) stable average happiness; and (3) falling happiness inequality.

We have shown that these cannot be explained by income inequality or socio-demographic characteristics. We now consider the existing theories of the link between income and happiness to see whether they fit this pattern.

has been flat or declining in the 1990's and has remained incomparably lower than the increase in income inequality (see Stevenson and Wolfers, $2008 \mathrm{~b}$ for a review). 


\section{IV.1. Happiness as a log function of (absolute) income and nothing else}

Stevenson and Wolfers (S\&W) have argued that the relationship - both cross-section and time-series - between income and happiness is characterized by a stable log function. Does this fit our stylized facts?

Suppose, to start, that average income growth leaves the distribution of income invariant, i.e. all incomes increase proportionally. In this case, average happiness would rise (although perhaps not spectacularly, due to concavity) and the standard deviation in happiness would remain constant (as the standard deviation is translation invariant, and the log of a product is a sum of the logs). Hence, in order to produce the stylized facts, the distribution of income has to change. However, the only change in income distribution that would generate a meanpreserving fall in happiness inequality is a rise in the income of the poor matched by a greater fall in the income of the rich. This concentration of incomes around the median would leave average happiness constant and reduce its dispersion. However, this evolution has not been observed in any of the countries under review: it is rather the opposite that holds.

\section{Actual and counter-factual distributions of happiness}

A direct empirical test of S\&W consists in asking whether the happiness function, estimated at the beginning of a period of growth, in each country, correctly predicts the distribution of happiness, using the observed changes in income distribution and demographics, at the end of the period. This would be the case were individual happiness to be a stable function of individual income. However, this simulation exercise shows that the actual distribution of happiness at the end of the period is systematically different from that which is predicted. The actual distribution of happiness is always more concentrated around the mode, with thinner tails of the distribution, than that which is predicted (Figures 7.A - 7.D). In particular, in all of 
the countries under consideration, were the happiness function to be stable over time, more people would be at the highest level of the happiness scale than are actually observed.

\section{IV.2. Social comparisons}

Easterlin proposed two behavioral explanations of his happiness-level paradox: social comparisons and adaptation over time. We start with social comparisons, i.e. the hypothesis that happiness is at least partly relative in income. We hence assume that happiness depends on $\log \left(\mathrm{y}, \mathrm{y} / \mathrm{y}^{*}\right)$, where $\mathrm{y}$ is individual income, and $\mathrm{y}^{*}$ is reference income. We know, from Figures 6.A - 6.D, that average income in all quintiles has increased over the period, and that the income of the top quintile has rise substantially, leading to greater income inequality, and that the standard deviation of happiness within quintiles has fallen (except in the GSS, where it increases for the bottom quintile after 1990).

Under these conditions, if everybody compares to an ever increasing top income category, i.e. $\mathrm{y}^{*}$ increases over time by a comparable amount for everybody, well-being will fall for everybody (except the richest), yielding an increase in the standard deviation in happiness. Accordingly, van Praag (2011) notes that income inequality should create an increase in happiness inequality via an envy channel. Hence, a priori, with income comparisons, rising income inequality should lead to greater happiness inequality, rather than the opposite.

There are of course, in abstracto, any number of configurations that could lead to a happiness concentration, but these do not correspond to the actual change in the income distribution. Suppose, for instance, that the utility is only partly relative in income, that everybody compares to average or median income, and that this latter increases, whereas incomes at the extremes do not change: the additional happiness of the middle class will then be offset by lower happiness at the extremes. Reproducing the same reasoning "fractally", suppose that 
society is divided into separate groups, with comparisons within but not across groups, and that people compare to average income within each group. An analogous concentration of income within each group would then produce a similar result. Another possibility is that everybody compares to the poorest group (which itself compares to absolute poverty), and that the poorest group becomes richer over time while the incomes of all other groups remain the same: such pro-poor growth is consistent with our stylized facts.

However, empirical work seems to suggest that comparisons are mostly upward (see Clark et al. 2008 for a survey), and there is a consensus that the past three decades have not seen the enrichment of the middle class or the poorest, but rather of the richest. Our stylized facts would thus seem to require a rather subtle evolution of incomes and comparisons, whereby the richest would compare to an increasingly-distant target, while the poor progressively close the gap to their target group. However, we do not observe this kind of convergence in the average happiness of the different income quintiles within each country (Figures 6.A - 6.D). Overall, we do not have compelling evidence that the change in happiness results from income comparisons.

\section{IV.3. Adaptation}

The second behavioral explanation of the Easterlin paradox relies on adaptation, whereby individual aspirations grow in line with material affluence. As satisfaction is argued to depend on the gap between outcomes and aspirations, it will not change if this gap is unaffected. ${ }^{12}$

\footnotetext{
12 If adaptation is full-blown, it might be wondered why income is related to happiness at all. Easterlin (2001) hypotheses that all children and teenagers live together at the beginning of their lives and thus compare to each other and to each other's family wealth, which leads them to different happiness levels. Then, in adulthood, social groups are separated and no longer compare to each other, but remain on their specific satisfaction path.
} 
Adaptation implies a negative effect of past income on the utility of current income. ${ }^{13} \mathrm{Di}$ Tella and MacCulloch (2008) and Stutzer (2004) have shown evidence of total habituation to past income levels, so that the total impact of lagged and current income is zero. It is not however easy to see how adaptation could generate a fall in the inequality of happiness (with a constant mean). For instance, happiness equalization would occur were adaptation to be faster at the top of the income ladder and slower at the bottom, but in this case the mean level of happiness would rise.

We now ask whether more sophisticated concepts of adaptation are consistent with the observed stylized facts regarding the first and second moments of the distribution of happiness during episodes of growth.

\section{Bliss Points}

Another explanation for the Easterlin paradox, which is rejected by Easterlin himself (as well as Stevenson and Wolfers, 2008b, and Deaton, 2008), but accepted by others, such as Layard (2005), Inglehart (1997), Inglehart et al. (2008), Di Tella et al. (2010) and, more recently Proto and Rustichini (2012), is that the positive gradient in happiness disappears after a certain bliss point, ${ }^{14}$ located at around \$10 000 - \$15 000 per annum (Layard, 2005; Frey and Stutzer, 2002,), or \$26 000 - \$33 000 (Proto and Rustichini, 2012). The hypothesis of a satiation point is a particular case of adaptation, as it postulates complete adaptation above a certain income threshold.

Although the idea of a satiation point is controversial, we should see whether it can explain the stylized facts analyzed in this paper. We believe that it cannot. If only the rich become

\footnotetext{
${ }^{13}$ Another type of adaptation is that of changing aspirations, not because of one's own past experience, but from other people's standard of living, a concept that is close to comparisons (see section IV.2).
} 
richer (but no happier, because they are beyond the bliss point), this will not reduce happiness inequality. If all incomes increase and progressively reach the bliss point beyond which income ceases to yield happiness, then average happiness would rise until everybody reaches the bliss point; the same holds if only the poor become richer.

\section{Maslow and post-modern values}

Another more sophisticated version of adaptation is the evolution of needs and aspirations $\grave{a}$ la Maslow. Maslow (1943) proposed a model of the stages of development of human needs, motivations or aspirations. The most basic needs are (1) physiological needs (air, food, drink, shelter, warmth, sex and sleep) and (2) safety needs (protection, security, order, law, stability and limits); then come more elaborate needs such as (3) belongingness and love (family, affection, relationships and work group), (4) esteem (achievement, status, responsibility and reputation), and (5) self-actualization (personal growth and fulfillment). The first two types of needs create physiological distress in the case of deficiency and physiological bliss when they are fulfilled, whereas the three subsequent needs are "meta-motivations" of a superior kind. Maslow suggests that the most basic level of needs must be met before the individual desires (or focuses their motivation on) the secondary or higher-level needs, although the five types of needs may overlap. Maslow's theory can be translated into the framework of economics by suggesting that subjective well-being depends on the multidimensional gap between needs and attainments, but with the weights attached to each dimension depending on the context and level of affluence. As individuals fulfill their basic needs, they take them for granted, and reduce the importance attached to this dimension. They then start attaching more importance to the other dimensions, for which the gap between needs and outcomes remains considerable.

\footnotetext{
${ }^{14}$ One question is of course whether this bliss point would not increase with the country's level of affluence. For instance, Proto and Rustichini (2012) calculate that the level of this threshold is around \$26000-\$30000 for all countries in the World Values Survey, but between $\$ 30000-\$ 33000$ for EU countries.
} 
Maslow thus implies a "preference drift" (van Praag, 1971) not only in the dimension of income, but also in a number of other life dimensions.

One important point is that the three higher needs may be more difficult to fulfill than the two basic needs. This recalls the distinction between survival and living. It would seem uncontroversial that being happy about the meaning of one's life is less straightforward than being happy to survive. Inglehart (1997, pp. 64-65) illustrates this opposition between survival and modern societies: "the transition from a society of starvation to a society of security brings a dramatic increase in subjective well-being. But we find a threshold at which economic growth no longer seems to increase subjective well being significantly. This may be linked with the fact that, at this level, starvation is no longer a real concern for most people. Survival begins to be taken for granted [...] At low levels of economic development, even modest economic gains bring a high return in terms of caloric intake, clothing, shelter, medical care and ultimately in life expectancy itself. [...]. But once a society has reached a certain threshold of development ... [...] non-economic aspects of life become increasingly important...”. Inglehart proposes an explanation in a recent paper (2010, p. 353): “Economic development increases people's sense of existential security, leading them to shift their emphasis from survival values towards self-expression values and free choice. [..] Emphasis on freedom increases with rising economic security”.

This theory implies that, as societies develop, the share of the population fulfilling their basic needs increases, and that still facing survival risks shrinks. However, as long as there remains some precariousness in society, the poor may feel happy to escape it, and their aspirations may reflect a mix of material and non-material needs. This would explain why average happiness does not increase while the percentage at the extreme happiness levels falls (individuals are more difficult to satisfy, but the poor are happy to escape material distress). 
A recent paper by Proto and Rustichini (2012) suggests that neurotic individuals at the top of the income scale are driving the Easterlin paradox, because of their particular tendency to adapt. Even absent this assumption (about neuroticism), it is likely that growth and technological progress increase the possibilities and aspirations of the wealthiest. At the same time, development brings extended access to basic goods (corresponding to basic needs 1 and 2). Modern growth is typically associated with a better general level of education and health, greater life expectancy at birth, less child mortality, more public infrastructure, and the extension of a social welfare system that provides insurance against the major risks of life (illness, unemployment and retirement). It is thus possible that the share of the population that feels totally deprived (the bottom of the scale) and totally satisfied (the top of the scale) both shrink. This is consistent with what we observe in the data.

\section{Rescaling}

Adaptation of needs à la Maslow is difficult to distinguish from another phenomenon: that of rescaling. Rescaling is a type of adaptation that does not concern latent satisfaction, i.e. the relationship between income and the actual level of happiness, but rather the relationship between latent happiness and self-declared happiness. The fact that happiness is very often measured on a bounded scale leads us to suspect that the meaning of the scale is contextdependent, i.e. the interpretation given to each step of the scale changes with the general context. Quoting Deaton (2008, p.70): “The 'best possible life for you' is a shifting standard that will move upwards with rising living standards". The intuition is that, as the world of opportunities changes, people also change their understanding of what maximum possible happiness represents (that associated with the tenth rung of the happiness ladder), and the worst possible situation (the lowest rung of the ladder), and more generally of what the steps of the happiness ladder mean. But this does not necessarily mean that they are less happy with 
what they have (which would be classic adaptation). The notion of the satisfaction treadmill, as opposed to the hedonic treadmill, captures this idea (Frederick and Loewenstein, 1999, Frederick, 2007).

One scenario that would fit our stylized facts is that people "rescale" more at the top of the ladder than at the bottom, because their world of opportunities expands more than that of the less wealthy. This would create convergence whereby the self-declared happiness of the poor would rise whereas that of the rich would not.

In sum, even if it is difficult to disentangle adaptation from rescaling, and even if both are reminiscent of Maslow's theory of needs, these theories predict that adaptation is stronger at the top of the social scale, which is consistent with the decreasing spread of happiness over time.

\section{Social equality and social expenditure}

A last channel yielding the stylized facts is that from the externalities of economic growth and modernization. In many Western countries, economic development has been accompanied by the creation and extension of a welfare system, which stricto sensu consists of social insurance against major life risks (health, unemployment and retirement insurance) and the provision of social transfers, but more generally brings improvements in the realm of education, health, life expectancy, child mortality, etc. Along these lines, Table 1.A shows that the share of social spending in national GDP reduces the variance in happiness in World Values Survey countries.

But modern growth comes along with other types of benefits: material public goods such as infrastructure for transportation and communication, but also non-material public goods, such 
as reduced violence and crime, the benefit of living in a country where people are more educated, greater freedom of choice in private life, political freedom, transparency and pluralism, better governance, etc. Some authors, e.g. Ott (2005), underline the negative correlation of measures of the quality of institutions and governance (including democracy, freedom and government effectiveness), as well as gender-empowerment measures, with happiness inequality. Veenhoven (2005b) attributes the fall in happiness inequality in EU countries, 1973-2001, to the hypothesis that any inequality in resources has been more than compensated by greater equality in personal capabilities. Ovaska and Takashima (2010) regress happiness inequality on socioeconomic controls and income distribution, as well as economic and political freedom measures taken from the Fraser Institute and Freedom House. Their country-level regressions show that the standard deviation in national happiness across WVS countries falls with the different indices of political freedom.

All of these political, economic and social changes can be seen as public goods, i.e. amenities accessible to all of a country's inhabitants (although they may marginally differently benefit different population groups). It is straightforward that the increased provision of public goods will reduce the happiness spread across the population. ${ }^{15}$ This extension of the positive externalities of modern growth cannot however explain why average happiness should be flat over time. Hence, this hypothesis alone cannot explain our stylized facts; it has to be considered together with adaptation or rescaling.

\footnotetext{
${ }^{15}$ Technically, the extension of the sphere of public goods is equivalent to increasing every citizen's consumption by a similar positive amount. If happiness is a log function of consumption, this will naturally reduce the dispersion of happiness across individuals.
} 


\section{Conclusions}

In spite of the great U-turn (Veenhoven, 2005b) that saw income inequality rise in Western countries in the 1980s, happiness inequality is falling in modern societies. We provide international evidence of this evolution using information from the World Values Survey and country-specific surveys of Australia, Great Britain, Germany and the United States. The decline in the spread of happiness comes as a second-moment complement to the firstmoment Easterlin paradox (the stability of average happiness over long periods of income growth). Taken together, these two stylized facts are difficult to explain under the hypothesis that individual happiness is a stable concave function of income. More behavioral hypotheses, such as income comparisons and simple adaptation over time also seem to be insufficient. However, Maslow-style adaptation and rescaling are both consistent with these changes. The extension of public amenities brought about by modern growth may well also have contributed to this homogeneity of happiness in modern nations.

The interpretation we offer of the new "augmented" Easterlin paradox brings a less pessimistic vision of development. If raising the income of all may not raise the happiness of all, it will at least reduce the gaps between them, provided that income inequality is not too large. Although the current state of data availability makes it easier to establish this new conjecture about the concentration of happiness for developed countries, this perspective is more promising for developing countries, as it allows the benefits of modern growth and a robust welfare system to accrue to all concerned. 


\section{References}

Atkinson, T. Piketty, T. and Saez, E. (2011). “Top Incomes in the Long Run of History”, Journal of Economic Literature, 49, 3-71.

Becchetti L., Massari R. and Naticchioni P. (2011). "The drivers of happiness inequality. Suggestions for promoting social cohesion”, Università di Cassino, Dipartimento di Scienze Economiche, WP No. 6/2011.

Beegle K., Himelein K. and Ravallion M. (2009). "Frame-of-reference bias in subjective welfare regressions”. World Bank Policy Research Working Paper 4904.

Berry, K.J. and Mielke, P.W., Jr. (1992), “Assessment of variation in ordinal data”. Perceptual and Motor Skills, 74, 63-66.

Blinder, A. S. (1973). "Wage Discrimination: Reduced Form and Structural Estimates" Journal of Human Resources, 8, 436-455.

Clark, A.E., Frijters, P., and Shields, M. (2008). "Relative Income, Happiness and Utility: An Explanation for the Easterlin Paradox and Other Puzzles”. Journal of Economic Literature, 46, 95-144.

Clark, A.E., and Senik, C. (2011). "Will GDP Growth Increase Happiness in Developing Countries?” In R. Peccoud (Ed.), Measure For Measure: How Well Do We Measure Development? Paris: STIN.

Deaton, A. (2008). "Income, Health and Well-Being around the World: Evidence from the Gallup World Poll”. Journal of Economic Perspectives, 22, 53-72.

Di Tella, R., Haisken-De New, J., and MacCulloch, R. (2010). "Happiness adaptation to income and to status in an individual panel”. Journal of Economic Behavior \& Organization, 76, 834-852.

Di Tella, R., and MacCulloch, R. (2008). "Gross National Happiness as an Answer to the Easterlin Paradox?”. Journal of Development Economics, 86, 22-42.

Di Tella, R., MacCulloch, R., and Oswald, A. (2003). “The Macroeconomics of Happiness”. Review of Economics and Statistics, 85, 809-827.

Diener. E., Michalos A., Veenhoven R. and Cummins R. eds. (2005) "Special issue: Inequality of Happiness in Nations”, Journal of Happiness Studies, 6(4).

Dustmann C., Ludsteck J. and Schönberg U. (2008). "Revisiting the German Wage Structure”, Quarterly Journal of Economics, 124, 843-881.

Dutta I. and Foster J. (2011). “Inequality of Happiness in US: 1972-2008”, University of Manchester EDP-1110. 
Easterlin, R. (1974). "Does Economic Growth Improve the Human Lot?" In Nations and Households in Economic Growth. P. A. David and W. B. Melvin. Palo Alto, Stanford University Press: 89-125.

Easterlin, R. (1995). "Will Raising the Incomes of All Increase the Happiness of All?”. Journal of Economic Behavior and Organization, 27, 35-47.

Easterlin, R. (2001). "Income and Happiness: Towards a Unified Theory”. Economic Journal, 111, 465-484.

Easterlin, R. (2003). "Explaining Happiness”. Proceedings of the National Academy of Science, 100, 11176-11183.

Easterlin, R. (2005a). “Diminishing Marginal Utility of Income? Caveat Emptor”. Social Indicators Research 70, 243-255.

Easterlin, R. (2005b). "Feeding the Illusion of Growth and Happiness: A Reply to Hagerty and Veenhoven”. Social Indicators Research, 74, 429-443.

Easterlin R. and Angelescu L. (2009). "Happiness and growth the world over: time series evidence on the Happiness-income paradox”, IZA Discussion Paper No. 4060.

Easterlin R. and Angelescu L. (2010). "Modern Economic Growth: Cross Sectional and Time Series Evidence” in Kenneth C. Land, Ed., Handbook of Social Indicators and Quality of Life Research, New York and London: Springer.

Easterlin R. and Sawangfa O. (2010). "Happiness and Growth: Does the Cross Section Predict Time Trends? Evidence from Developing Countries”, in E. Diener, J. Helliwell, and D. Kahneman, eds. International Differences in Well-Being. Princeton, NJ., Princeton University Press, Chapter 7, pp. 162-212

Easterlin R. and Zimmermann A. (2006). "Life satisfaction and economic outcomes in Germany in pre and post unification”. IZA Discussion Paper No. 2494

Easterlin R. and Zimmermann A. (2009). "Lost in Transition: Life Satisfaction on the Road to Capitalism”. Journal of Economic Behavior and Organization, 71, 130-145.

Ferrer-i-Carbonell, A., and Frijters, P. (2004). "How important is methodology for the estimates of the determinants of happiness?”. Economic Journal, 114, 641-659.

Ferrer-i-Carbonell, A and van Praag B. (2003). "Income satisfaction inequality and its causes”, Journal of Economic Inequality, 1, 107-127.

Firpo S., Fortin N. and Lemieux T. (2009). "Unconditional Quantile Regressions”, Econometrica, 77, 953-973.

Frederick, S. (2007). “Hedonic Treadmill”. H-Baumeister (Encyc)-45348.qxd. 419-420.

Frederick, S., and Loewenstein, G. (1999). "Hedonic Adaptation”. In D. Kahneman, E. Diener, and N. Schwarz (Eds.), Well-being: The foundations of hedonic psychology. New York: Russell Sage Foundation. 
Frey, B.S., and Stutzer, A. (2002). "What Can Economists Learn from Happiness Research?” Journal of Economic Literature, 40, 402-435.

Galí, J. and Gambetti, L., (2009). “On the Sources of the Great Moderation”, American Economic Journal: Macroeconomics, 1, 26-57.

Gurr T.R. (1994). "Peoples against States: Ethnopolitical Conflict and the Changing World System”, International Studies Quarterly, 38, 347-377.

Heston, A., Summers, R. and Aten, B. Penn World Table Version 7.0, Center for International Comparisons of Production, Income and Prices at the University of Pennsylvania, May 2011.

Inglehart R. (1997). Modernization and Post-Modernization: Cultural, economic and political change in 43 societies, Princeton University Press.

Inglehart R. (2010). "Faith and Freedom: Traditional and Modern Ways to Happiness", Chapter 12, 351-397, in E. Diener, J. F. Helliwell, and D. Kahneman (eds.) International Differences in Well-Being, Oxford University Press.

Inglehart, R., Foa, R., Peterson, C., and Welzel, C. (2008). "Development, Freedom, and Rising Happiness: A Global Perspective (1981-2007)”. Perspectives on Psychological Science, 3, 264-285.

Kalmijn, W., and Veenhoven, R. (2005). "Measuring Inequality of Happiness in Nations: In Search for Proper Statistics”. Journal of Happiness Studies, 6, 357-396.

Kenny C. (2005). "Does development make you happy? Subjective well-being and economic growth in developing countries”. Social Indicators Research, 73, 199-219

Krueger, D. and Perri, F. (2006). "Does Income Inequality lead to Consumption Inequality?" Review of Economic Studies, 73, 163-193.

Layard, R. (2005). Happiness: Lessons from a New Science. London: Penguin.

Layard R., Mayraz G. and Nickell S., (2010). "Does Relative Income Matter? Are the Critics Right?” in E. Diener, J. F. Helliwell, and D. Kahneman (eds), International Differences in Well-Being, Oxford University Press.

Maslow, A. (1943). “A Theory of Human Motivation”. Psychological Review, 50, 370-396.

Oaxaca, R. (1973). “Male-Female Wage Differentials in Urban Labor Markets”. International Economic Review, 14, 693-709.

Ott J. (2005). "Level and Inequality of Happiness in Nations: Does Greater Happiness of a Greater Number Imply Greater Inequality of Happiness?”, in Diener et al. eds. "Special issue: Inequality of Happiness in Nations”, Journal of Happiness Studies, 6, 387-420.

Ott J. (2010). “Greater Happiness for a Greater Number: Some non-Controversial Options for Governments”, Journal of Happiness Studies, 11, 631-647. 
Ovaska T. and Takashima R. (2010). "Does a Rising Tide Lift all the Boats? Explaining the National Inequality of Happiness”, Journal of Economic Issues, 44, 205-224.

Polity IV Project: Political Regime Characteristics and Transitions, 1800-2009. Monty G. Marshall, Director Monty G. Marshall and Keith Jaggers, Principal Investigators, Center for Systemic Peace and Colorado State University; Ted Robert Gurr, Founder, University of Maryland, http://www.systemicpeace.org/polity/polity4.htm.

Proto, E. and Rustichini, A. (2012). "Life Satisfaction, Household Income and Personality Traits” The Warwick Economics Research Paper Series (TWERPS) 988, University of Warwick, Department of Economics.

Sacks, D., Stevenson, B. and Wolfers, J. (2011). "Growth in Income and Subjective Wellbeing over Time”. Mimeo.

Senik, C. (2004). "When Information Dominates Comparison: A Panel Data Analysis Using Russian Subjective Data”. Journal of Public Economics, 88, 2099-2123.

Senik, C. (2008). "Ambition and jealousy. Income interactions in the "Old" Europe versus the "New" Europe and the United States”. Economica, 75, 495-513.

Senik C. (2009). "Income Distribution and Subjective Well-being”, in OECD, Subjective well-being and social policy.

Stevenson, B., and Wolfers, J. (2008a), "Economic Growth and Subjective Well-Being: Reassessing the Easterlin Paradox”, Brookings Papers on Economic Activity, Spring.

Stevenson B. and Wolfers J. (2008b). “Happiness Inequality in the United States”, Journal of Legal Studies, 37, 533-579.

Stevenson, B. and Wolfers, J. (2010). “Inequality and Subjective Well-Being”, mimeo.

Stevenson, B. and Wolfers, J. (2011). “Trust in Public Institutions over the Business Cycle”, NBER Working Paper 16891.

Stock, J. and Watson M. (2002). "Has the business cycle changed and why?”. NBER Macroeconomics Annual, 17, 159-230.

Stutzer, A. (2004), “The Role of Income Aspirations in Individual Happiness” Journal of Economic Behavior and Organization, 54, 89-109.

Tullock G. (1971). “The paradox of revolution”, Public Choice, 11, 89-100.

Van Praag, B.M. (1971). "The Welfare Function of Income in Belgium: An Empirical Investigation”. European Economic Review, 2, 337-369.

Van Praag, B.M. (1991). “Ordinal and Cardinal Utility”. Journal of Econometrics, 50, 69-89.

Van Praag, B.M. (2007). "Perspectives from the Happiness Literature and the Role of New Instruments for Policy Analysis”, CESifo Economic Studies, 53, 42-68. 
Van Praag B. (2011). "Well-being inequality and reference groups: an agenda for new research”, Journal of Economic Inequality, 9, 11-127.

Van Praag, B.M. and Ferrer-i-Carbonell, A. (2006). “An Almost Integration-free Approach to Ordered Response Models”, Tinbergen Institute Discussion Paper 06-047/3.

Veenhoven R. (2005a). "Return of Inequality in Modern Society? Test by Dispersion of LifeSatisfaction Across Time and Nations”, Journal of Happiness Studies, 6, 457-487.

Veenhoven, R. (2005b). "Inequality of Happiness in Nations”, Journal of Happiness Studies, 6, 351-355.

Wagner, G., Frick, J., and Schupp, J. (2007). “The German Socio-Economic Panel Study (SOEP) - Scope, Evolution and Enhancements”. Schmollers Jahrbuch, 127, 139-169.

Wolfers, J. (2003). "Is Business Cycle Volatility Costly? Evidence from Surveys of Subjective Well-being”. International Finance, 6, 1-26. 


\section{Tables and Figures}

Figure 1.A. Happiness inequality and GDP per capita, in WVS countries

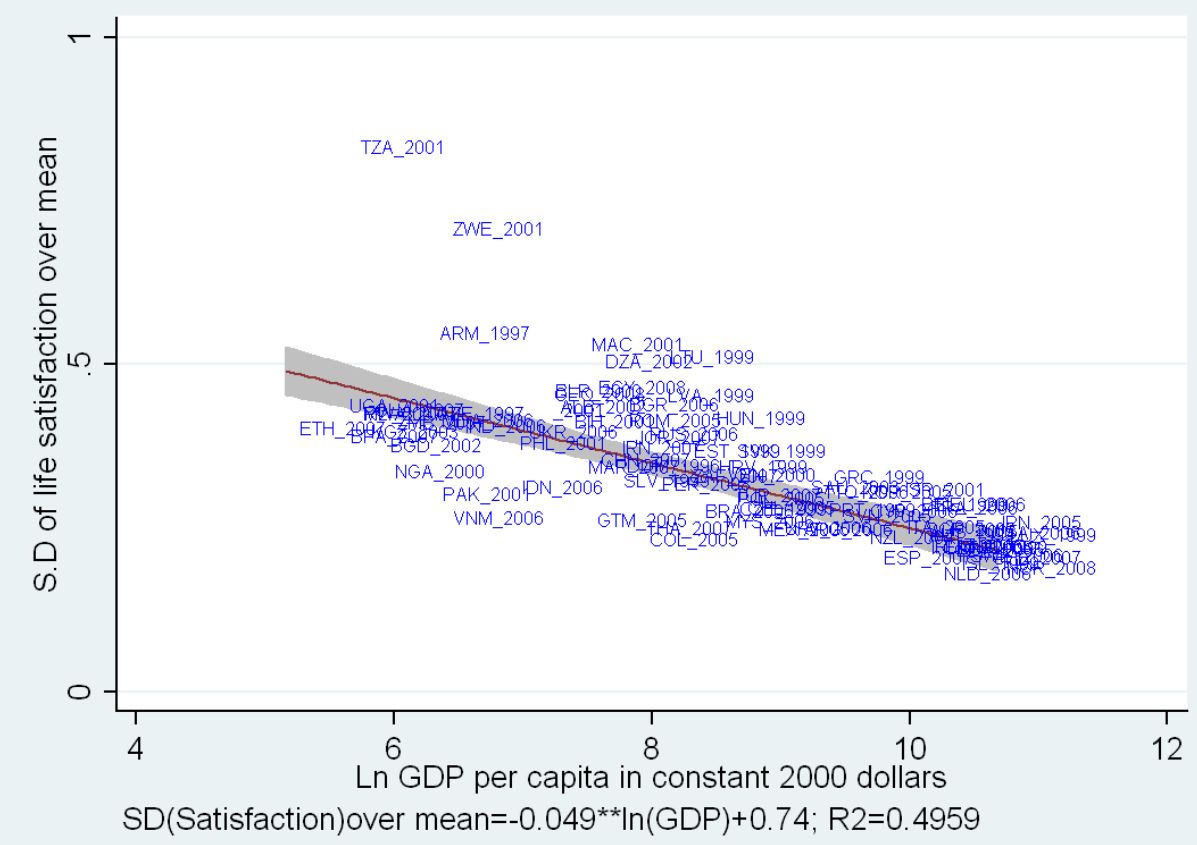

Note: GDP and average satisfaction are calculated for the last available WVS year for each country (between 2001 and 2008).

Figure 1.B. Happiness inequality and GDP per capita across rich and poor countries

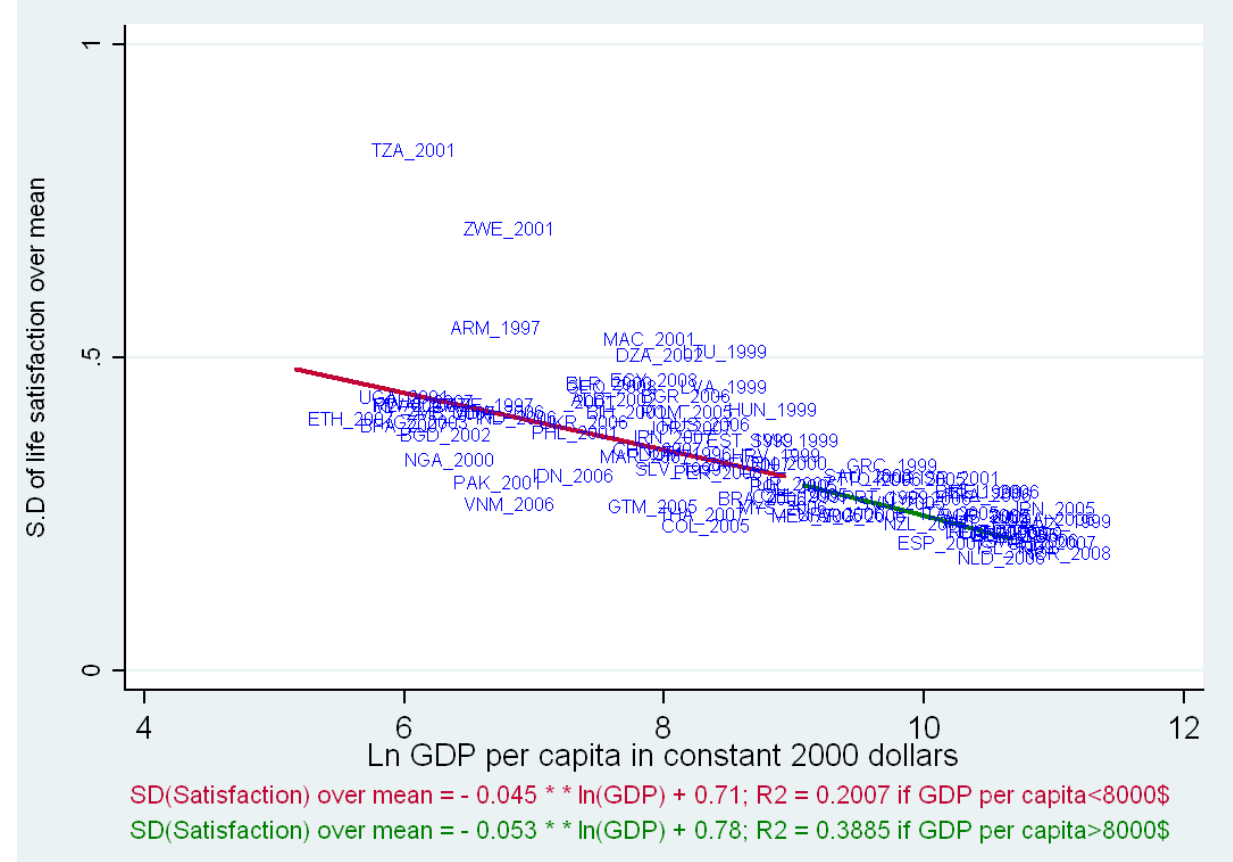

Note: GDP and average satisfaction are calculated for the last available WVS year for each country (between 2001 and 2008). 
Figure 2. Happiness inequality over time, Western countries (WVS)

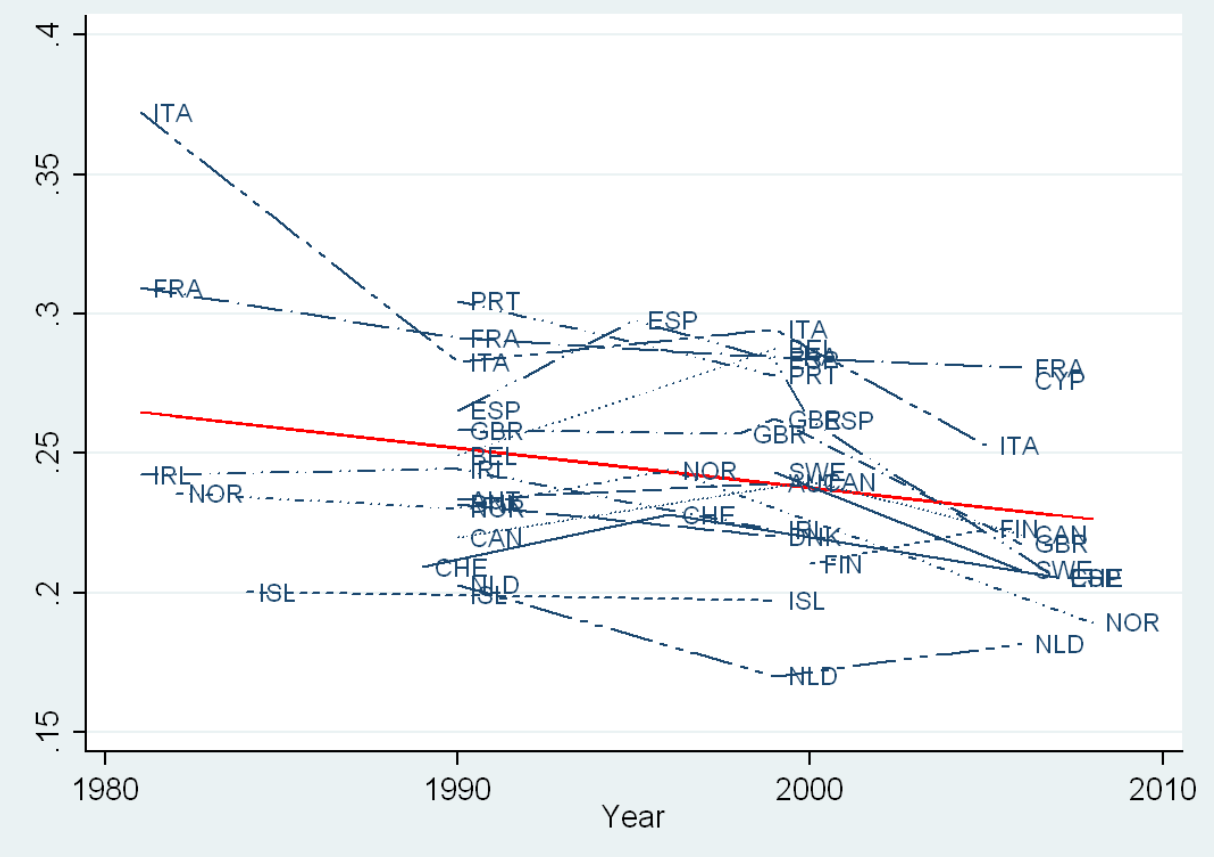

Note: Trends in Life-satisfaction inequality, during periods of strictly increasing growth, over periods of at least 5 years.

Figure 3.A Long run changes in happiness inequality and GDP per capita

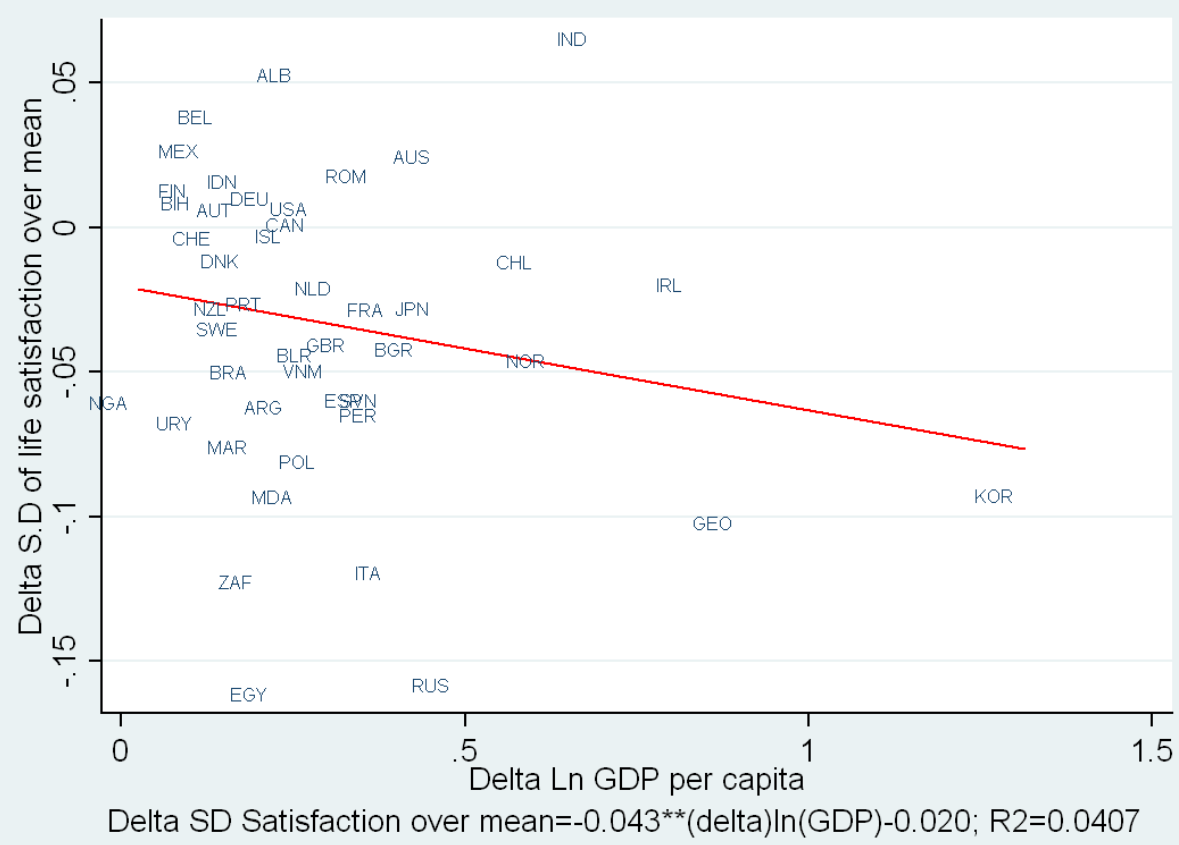

Note: Periods of strictly increasing growth, over at least 5 years. 
Figure 3.B Long run changes in happiness inequality and GDP per capita

\section{Western countries only}

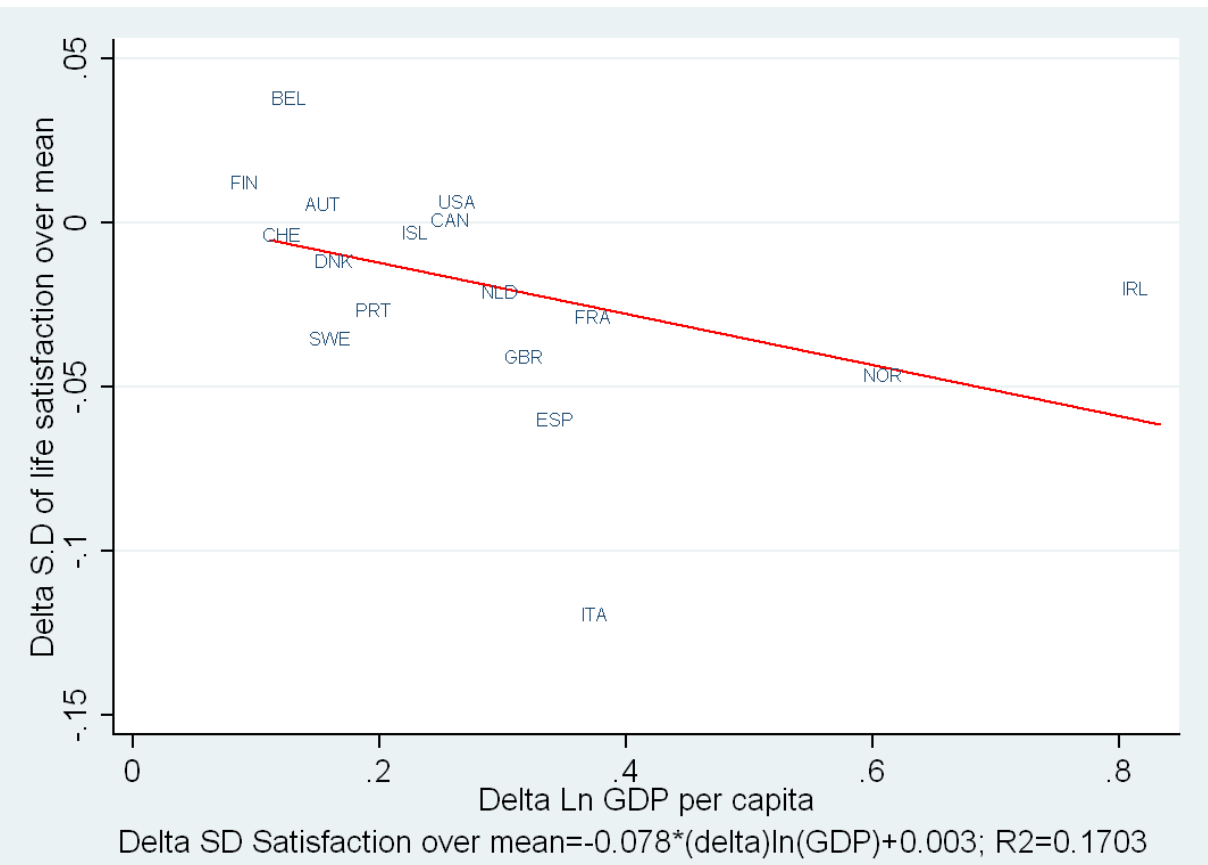

Note: Periods of strictly increasing growth over at least 5 years.

Figure 4.A The Trends in income growth, average happiness and happiness inequality: Great Britain (BHPS)
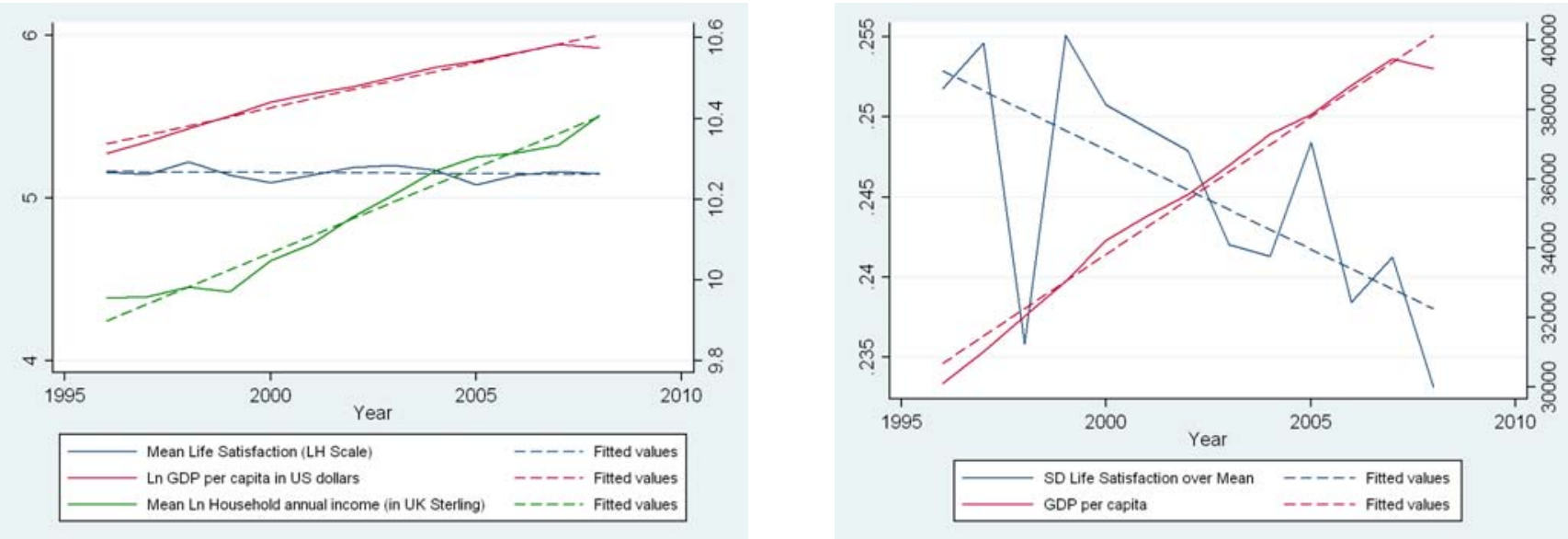
Figure 4.B The Trends in income growth, average happiness and happiness inequality: Germany (SOEP)
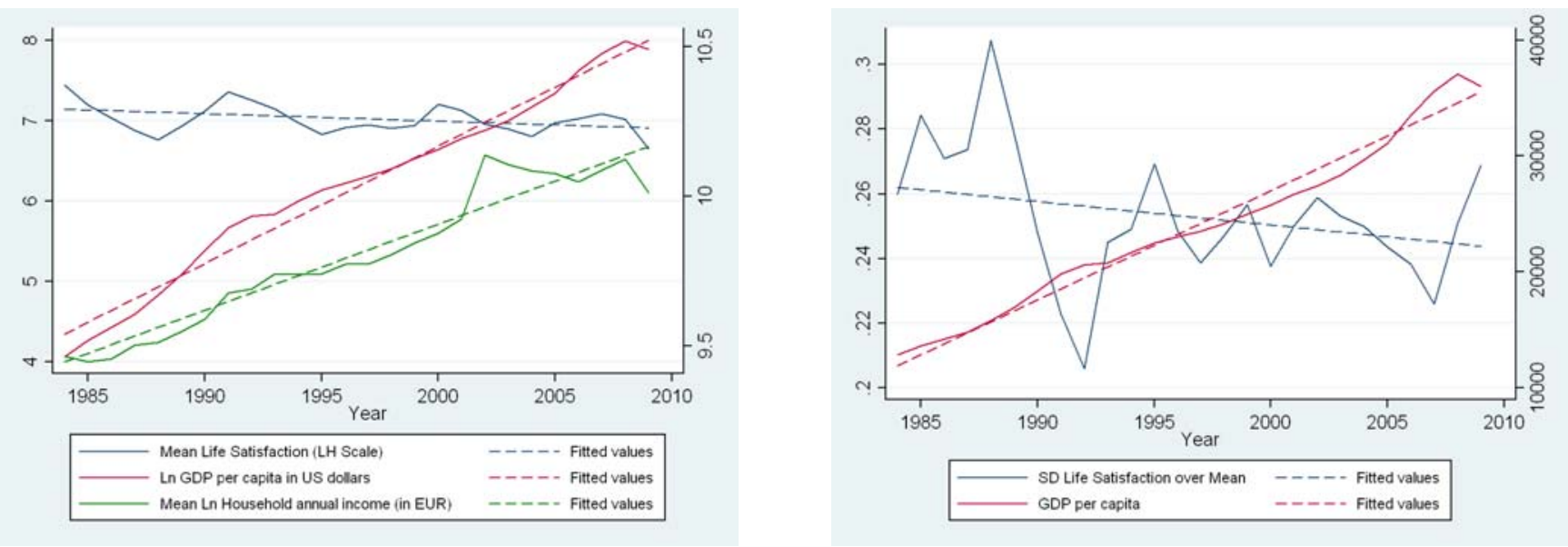

Figure 4.C The Trends in income growth, average happiness and happiness inequality: Australia (HILDA)
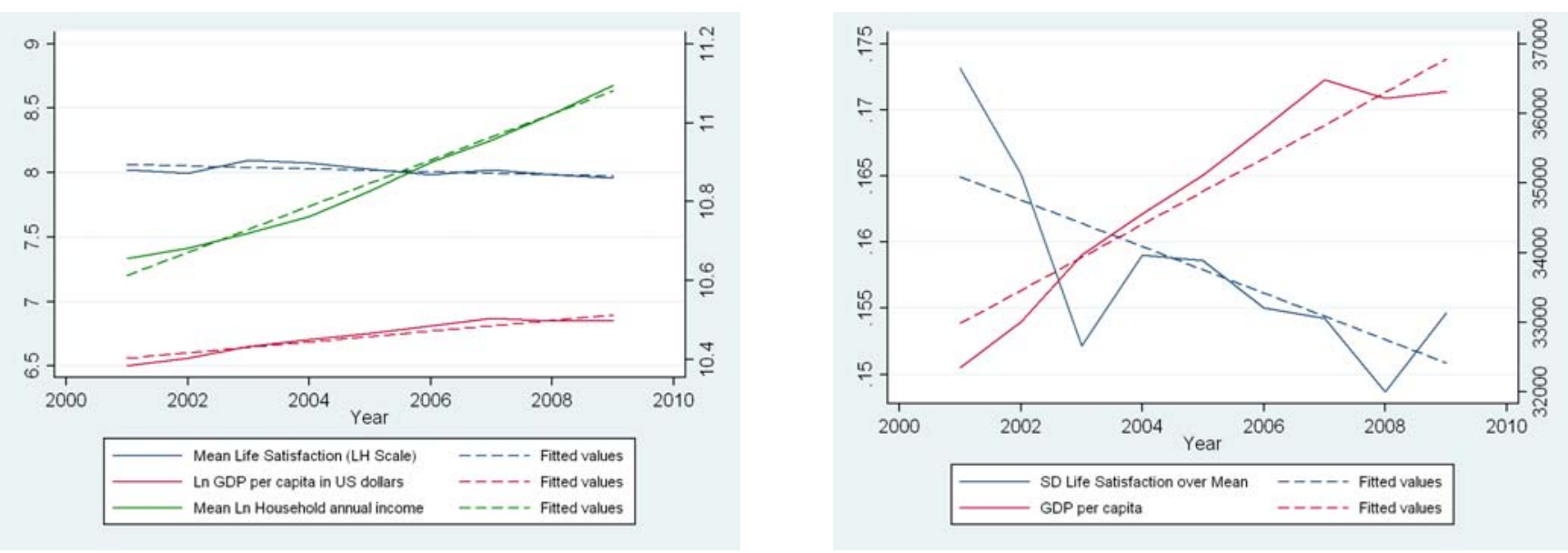

Figure 4.D The Trends in income growth, average happiness and happiness inequality:

\section{United States (GSS)}
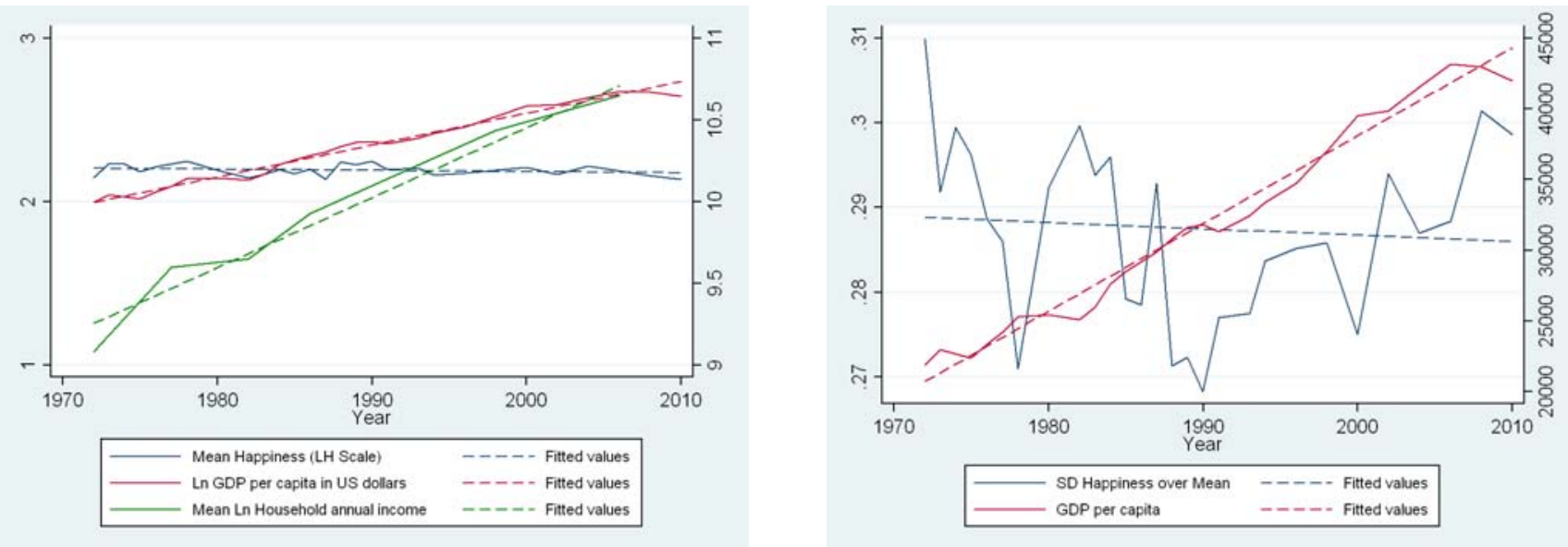
Figure 4.E The Trends in income growth, average happiness and happiness inequality in other countries of the WVS trends

Only countries with periods of at least 10 years with continuous positive income growth and constant happiness

\section{France}

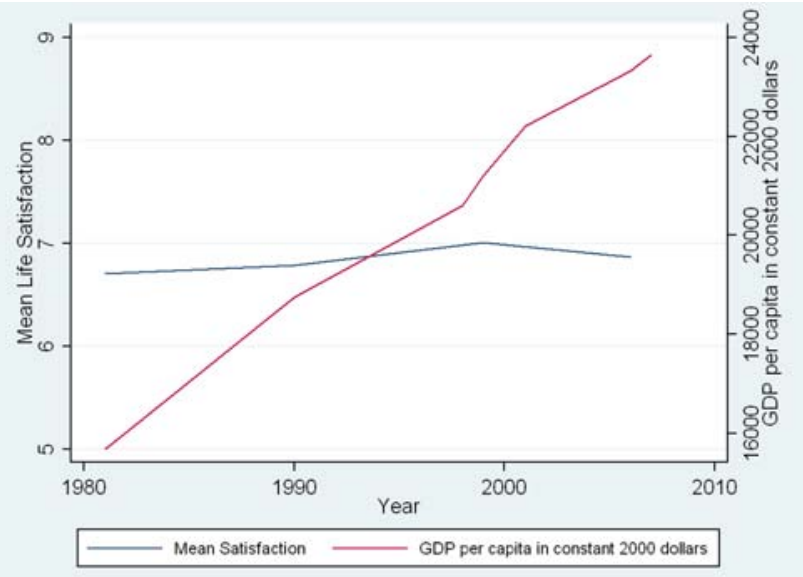

\section{Italy}

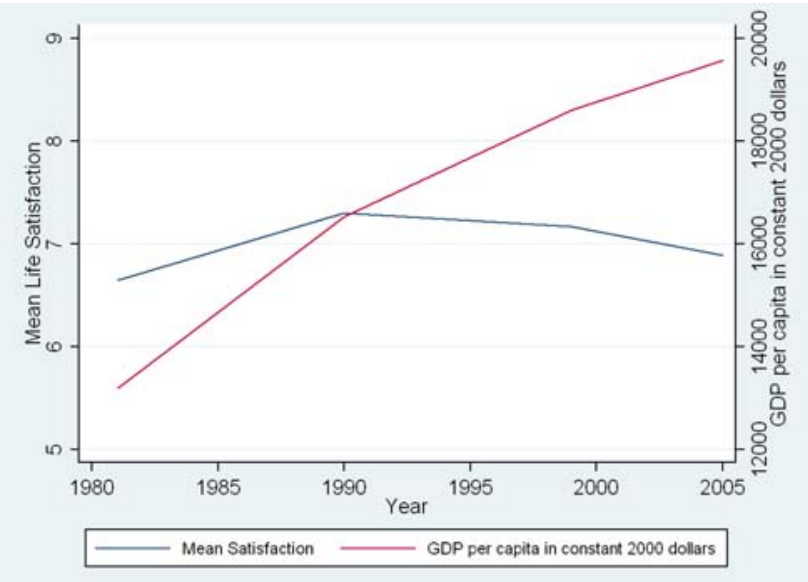

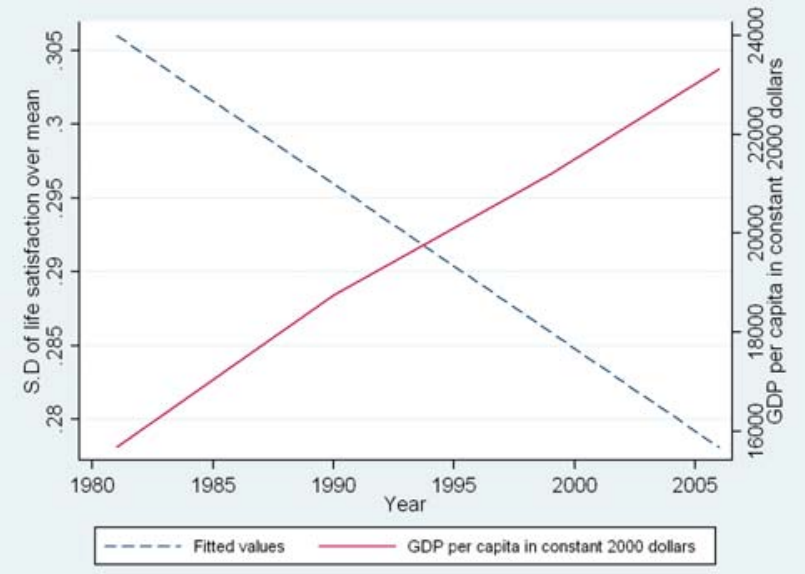

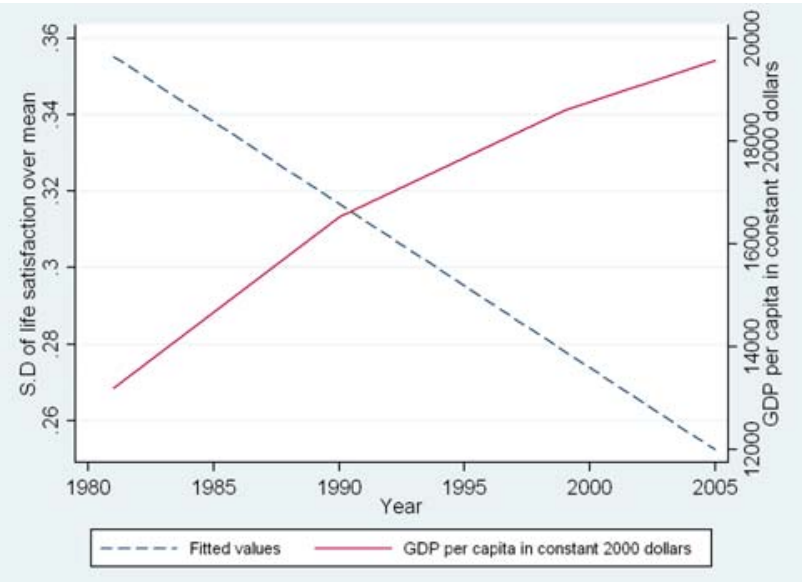

\section{The Netherlands}

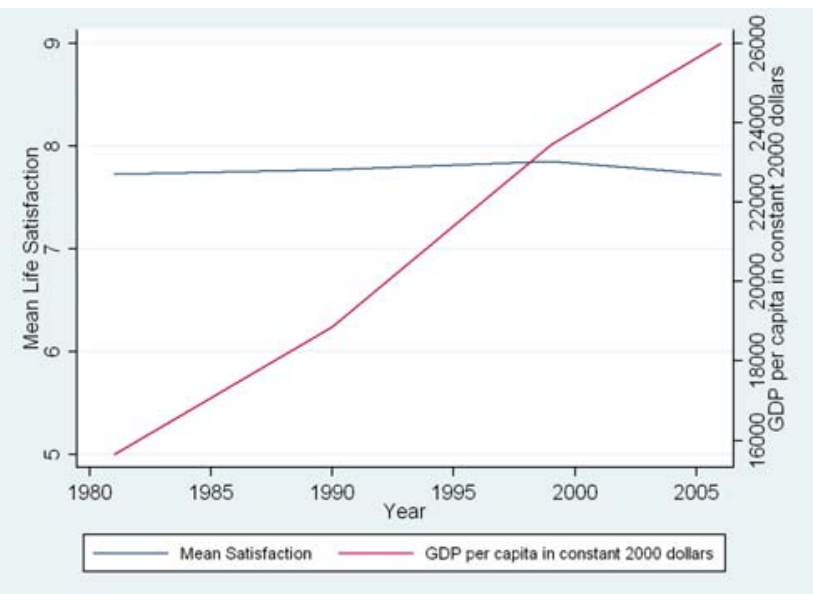

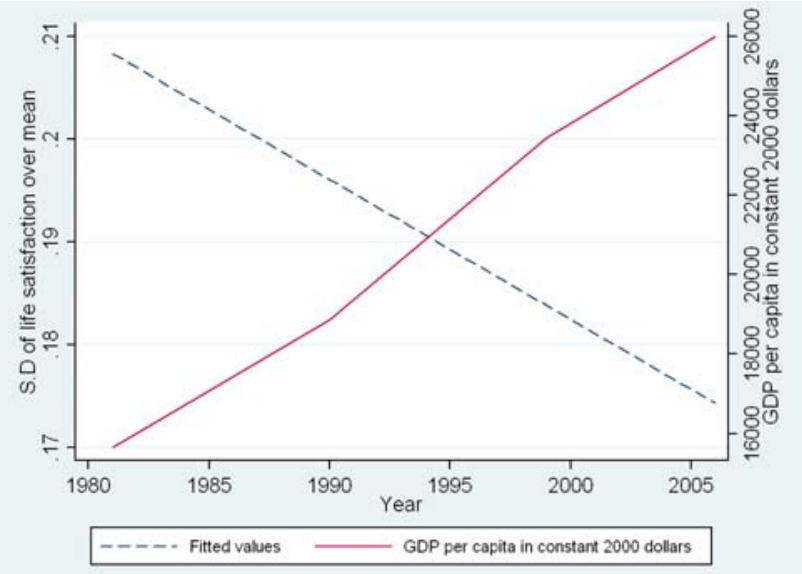


Norway

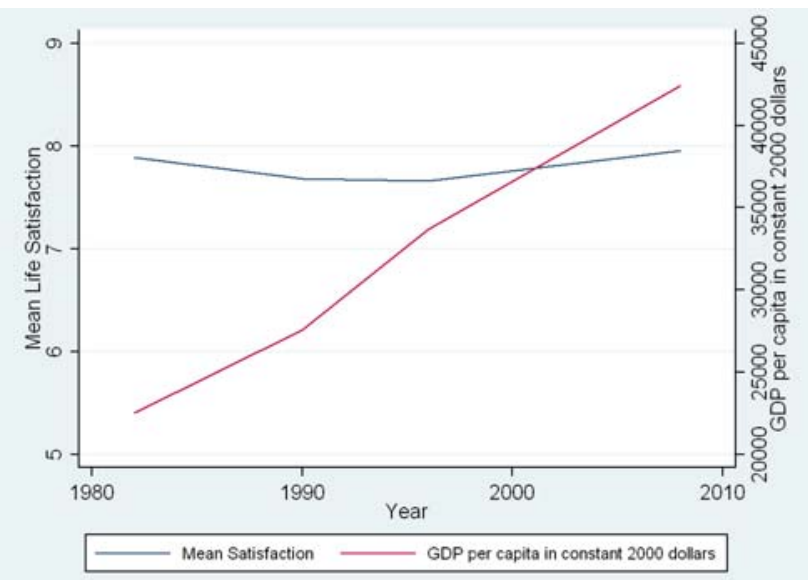

\section{Spain}

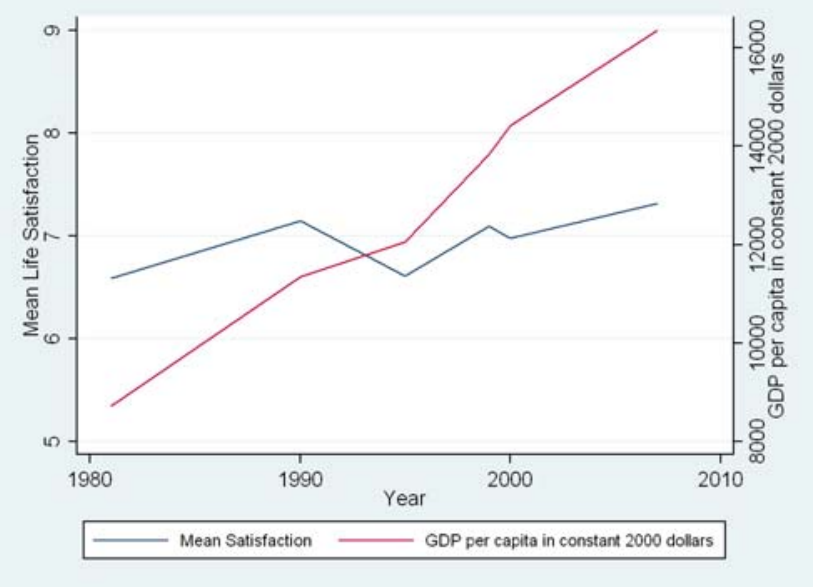

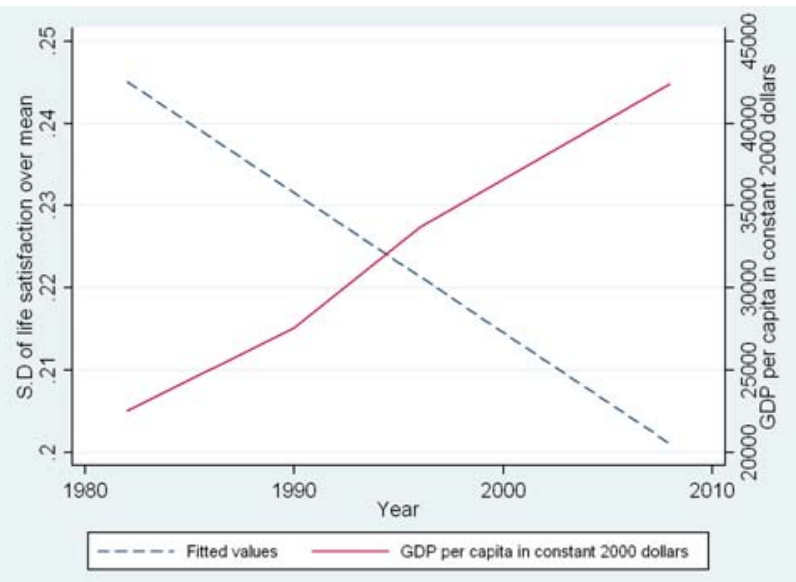

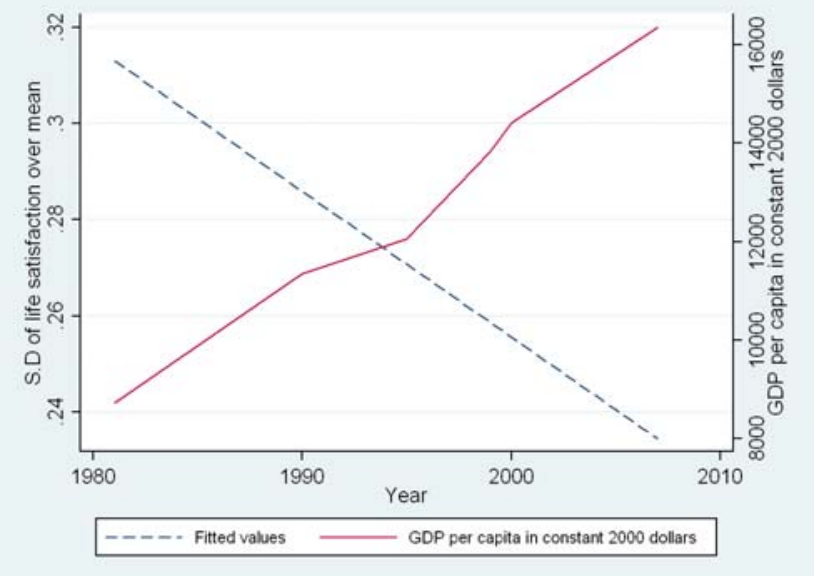


Figure 5.A The concentration of the happiness distribution: Great Britain (BHPS)
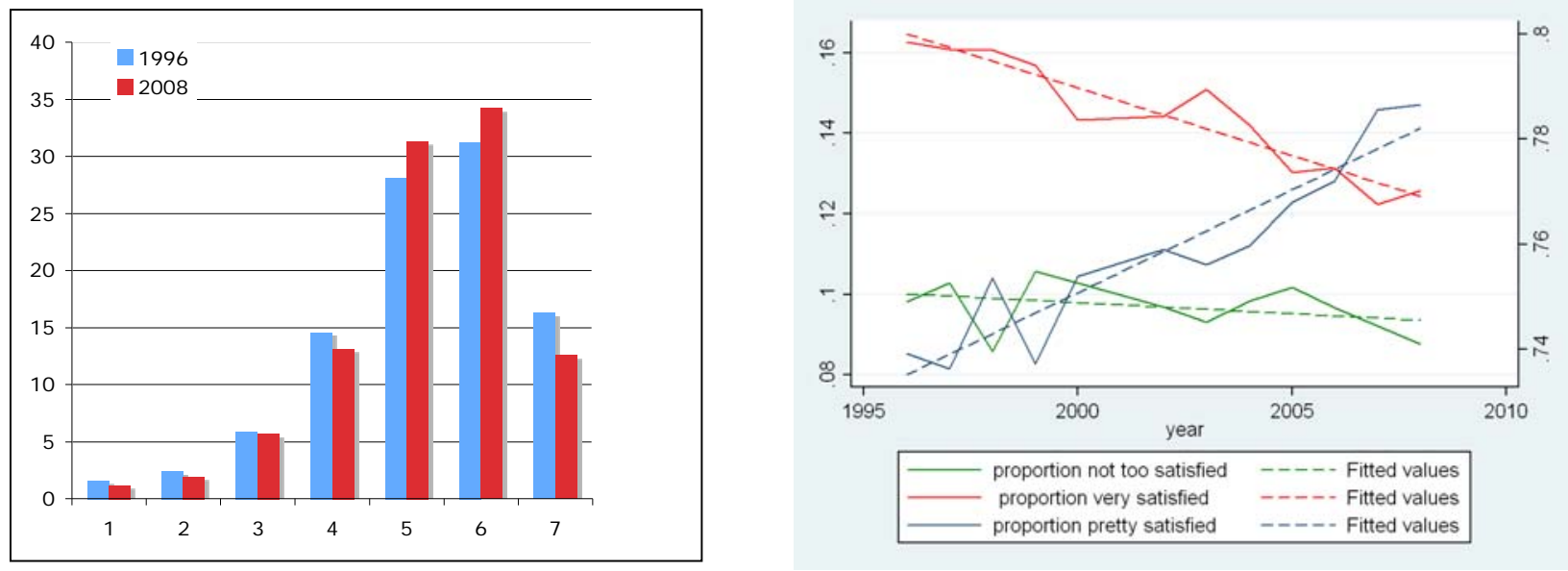

Note: Not too satisfied $=1-3 ;$ Pretty satisfied $=4-6 ;$ Very satisfied $=7$.

Figure 5.B The concentration of the happiness distribution: Germany (SOEP)
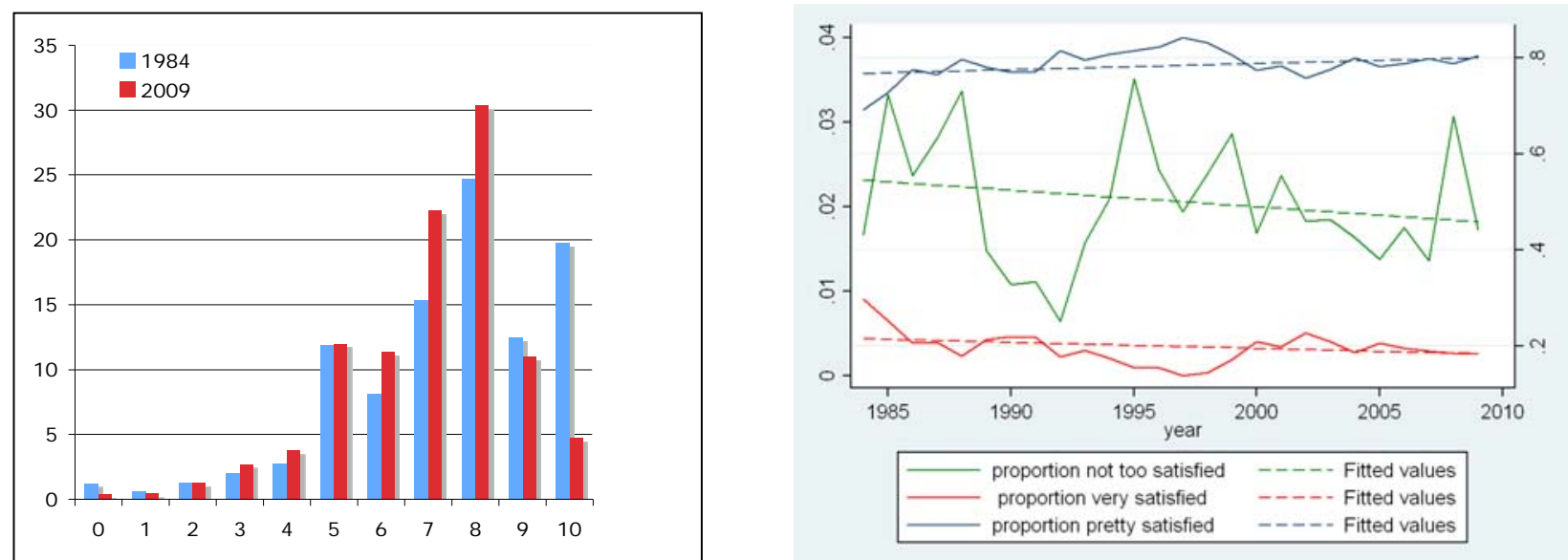

Note: Not too satisfied $=0-2 ;$ Pretty satisfied $=3-8 ;$ Very satisfied $=9-10$.

Figure 5.C The concentration of the happiness distribution: Australia (HILDA)
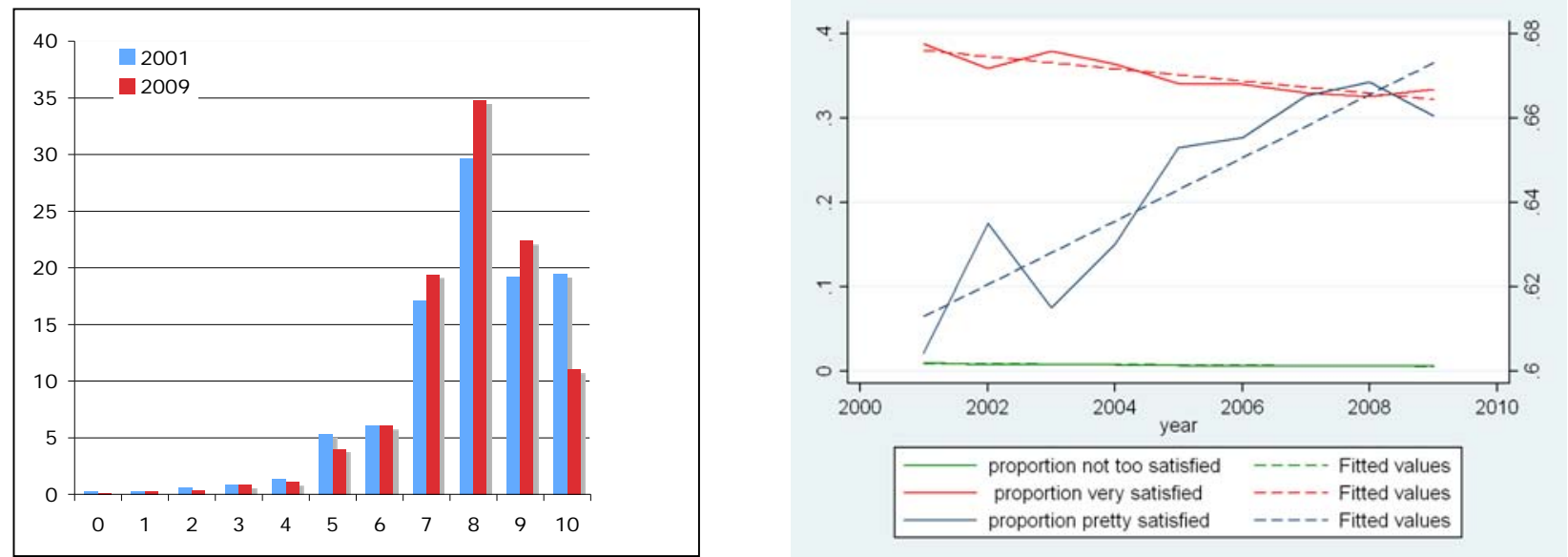

Note: Not too satisfied $=0-2 ;$ Pretty satisfied $=3-8 ;$ Very satisfied $=9-10$. 
Figure 5.D The concentration of the happiness distribution: USA (GSS)
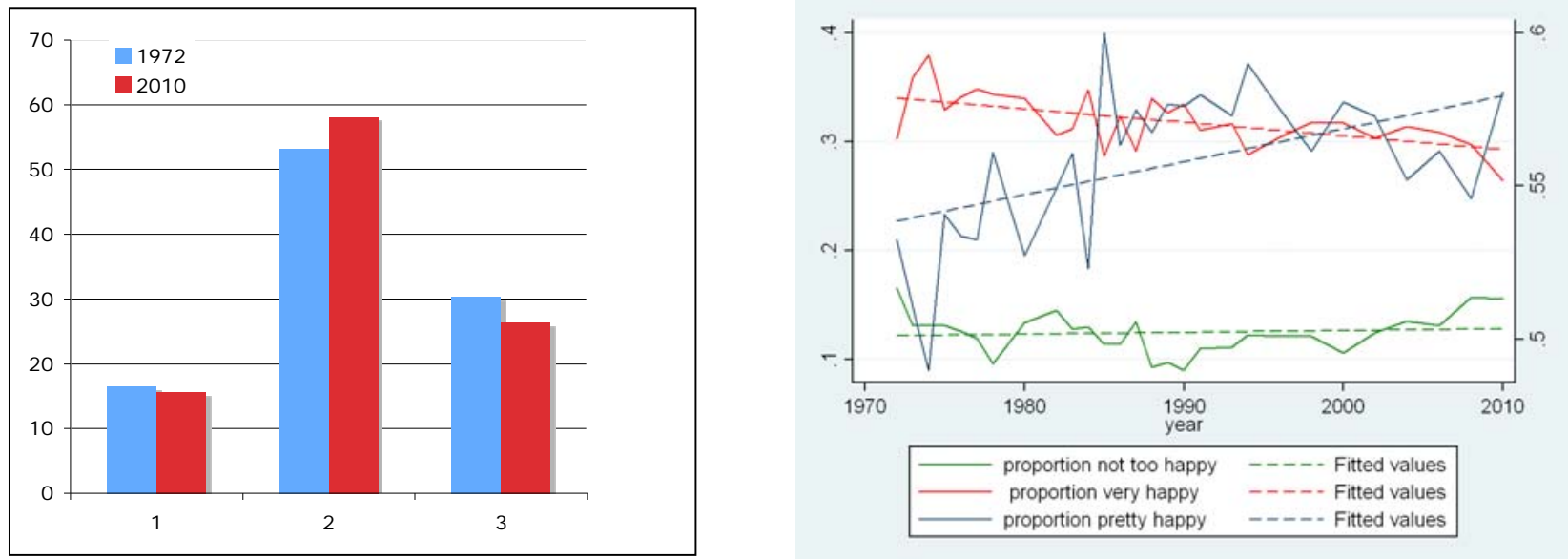

Figure 6.A Income inequality and happiness inequality: Great Britain (BHPS)
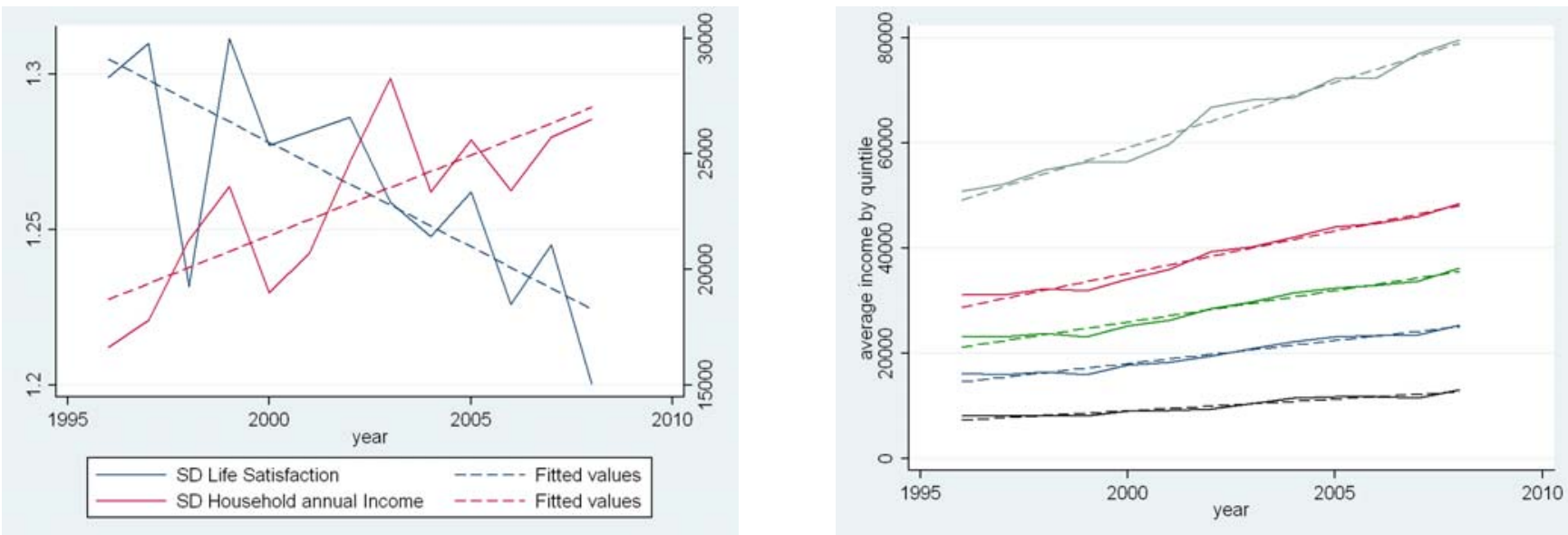

Legend: black (quintile 1), navy (quintile 2), green (quintile 3), cranberry (quintile 4), teal (quintile 5)

\section{Between}

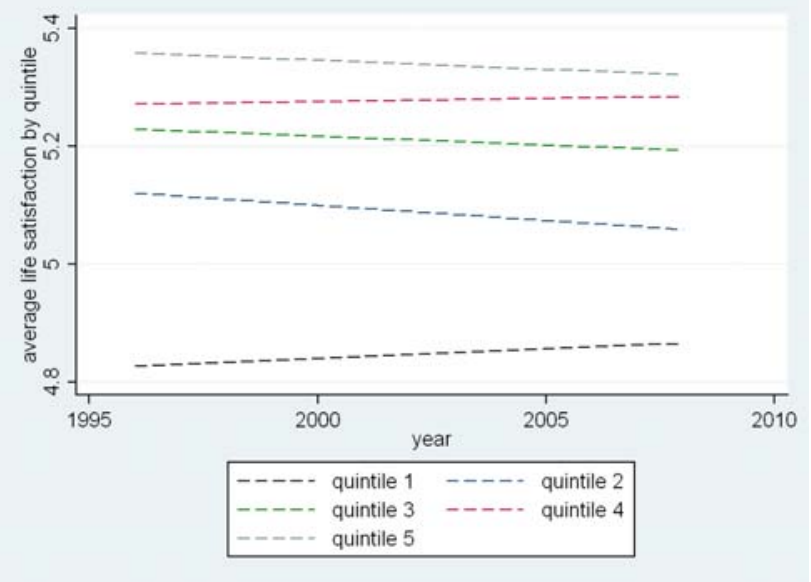

\section{Within}

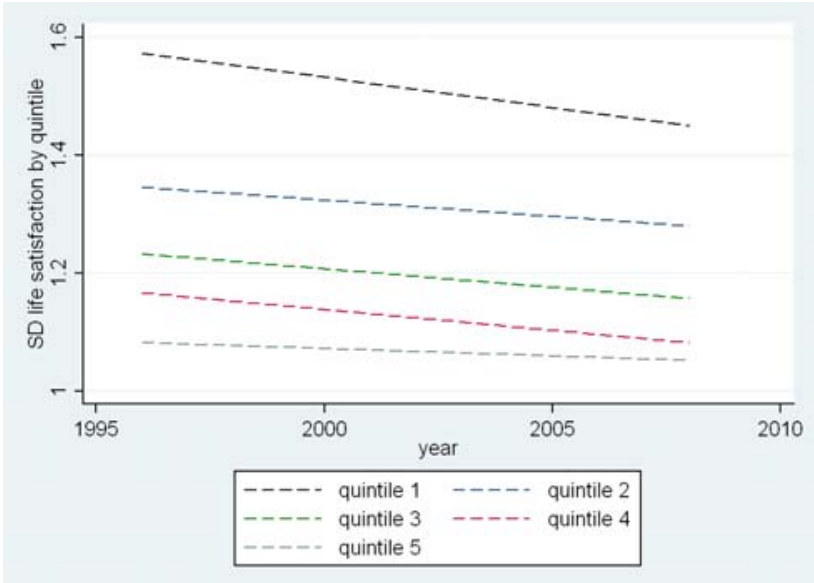


Figure 6.B Income inequality and happiness inequality: Germany (SOEP)
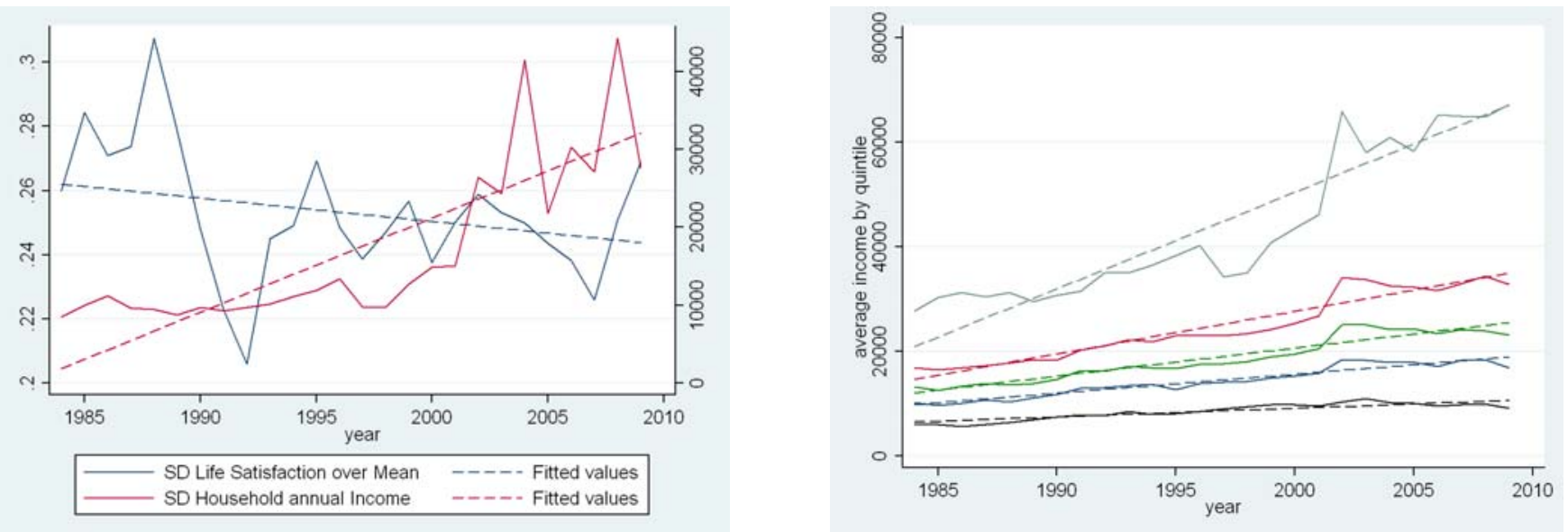

Legend: black (quintile 1), navy (quintile 2), green (quintile 3), cranberry (quintile 4), teal (quintile 5)

\section{Between}

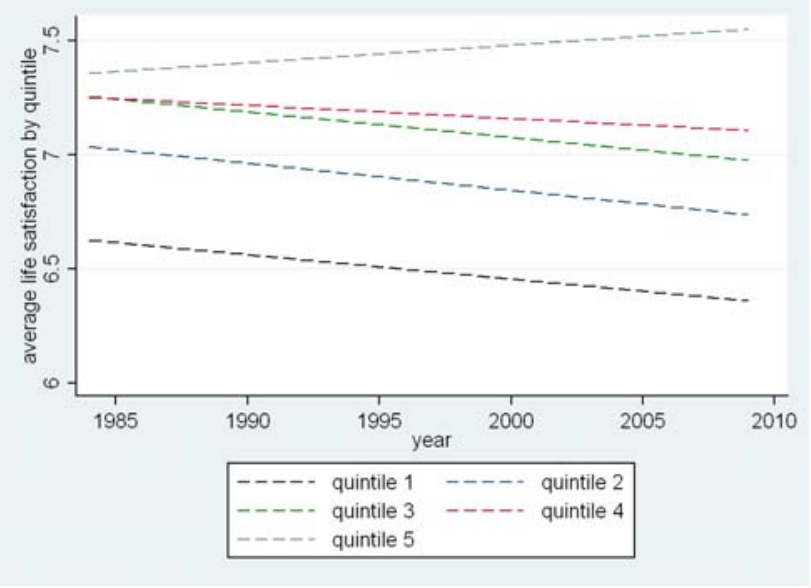

\section{$\underline{\text { Within }}$}

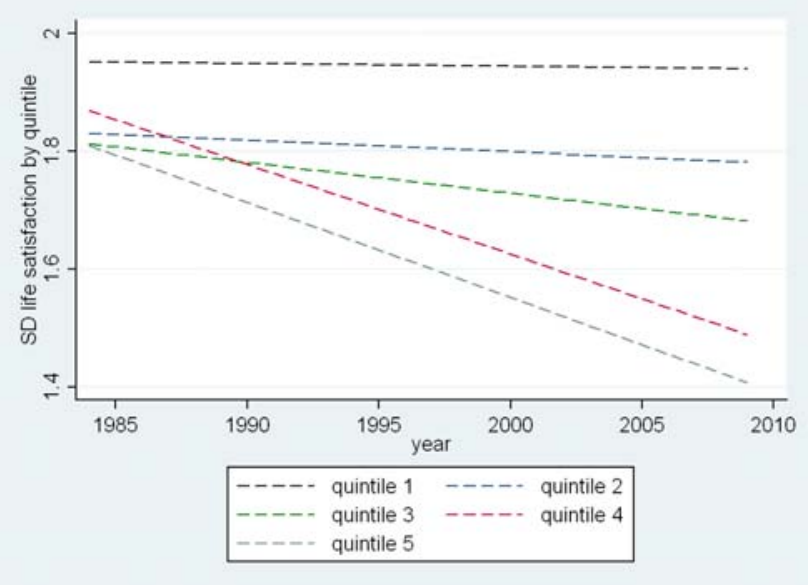


SOEP: 1984-1991
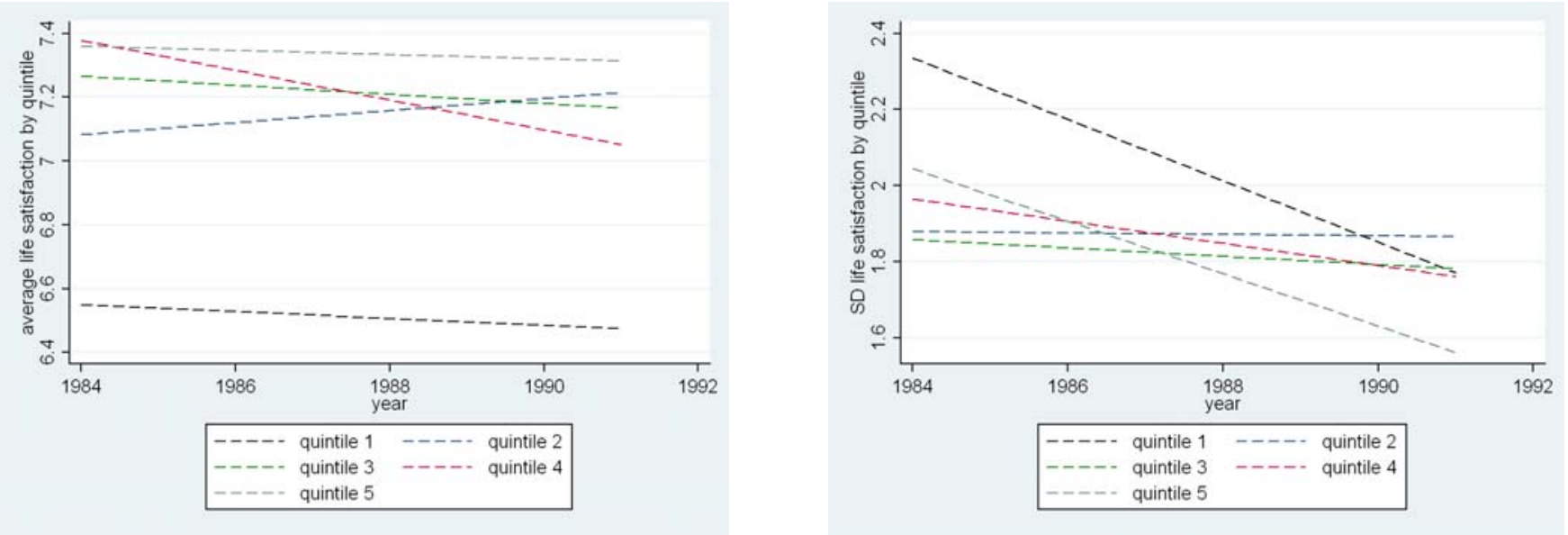

SOEP: 1992-2009

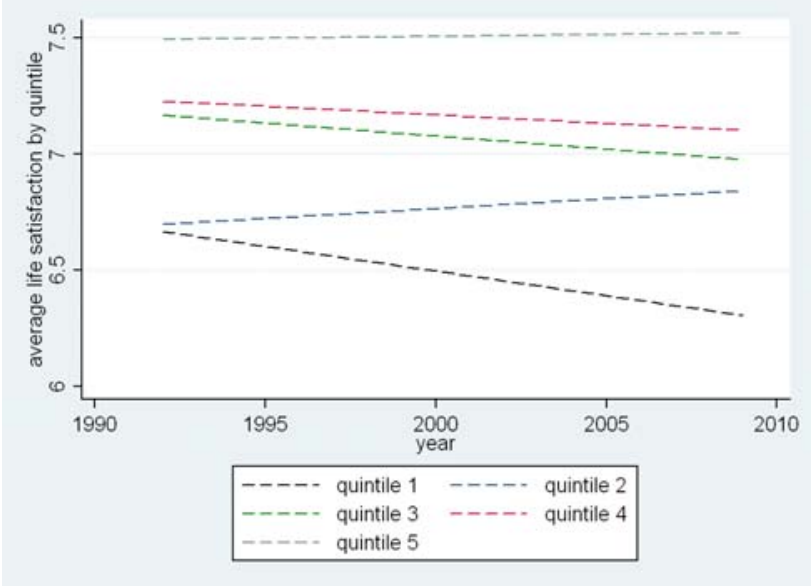


Figure 6.C Income inequality and happiness inequality: Australia (HILDA)
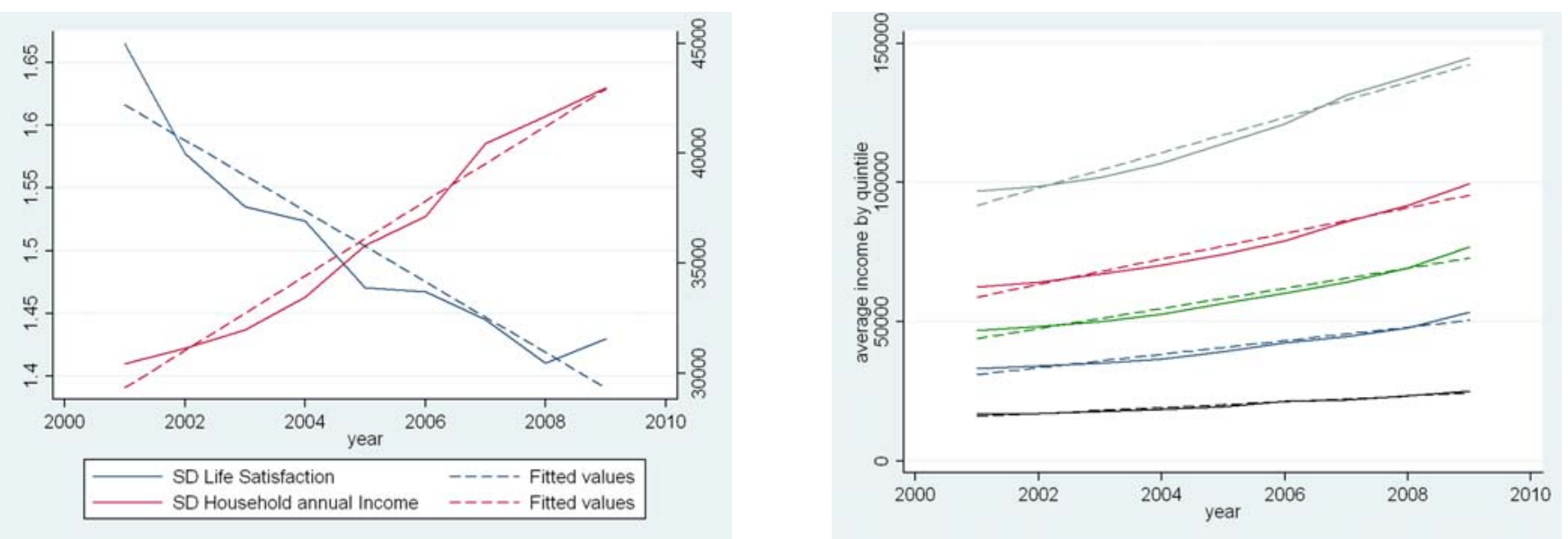

\section{Between}

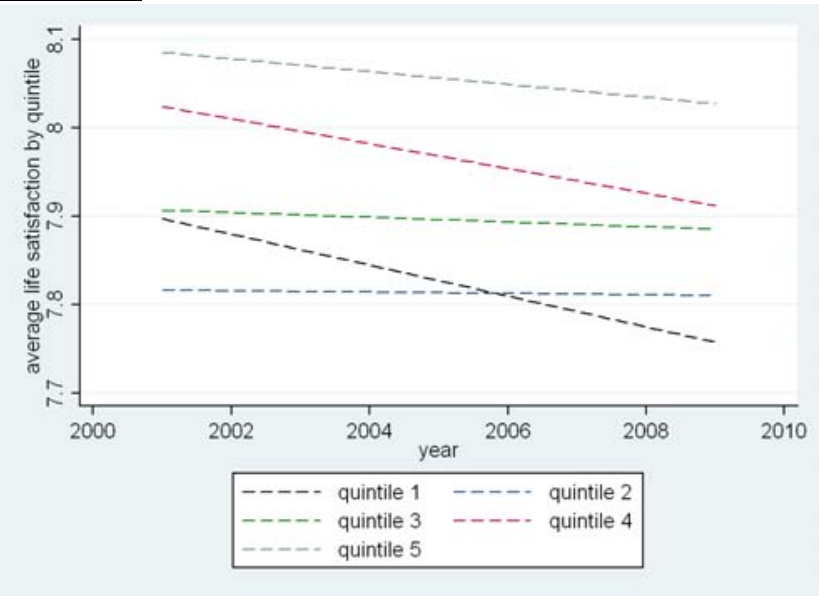

\section{Within}

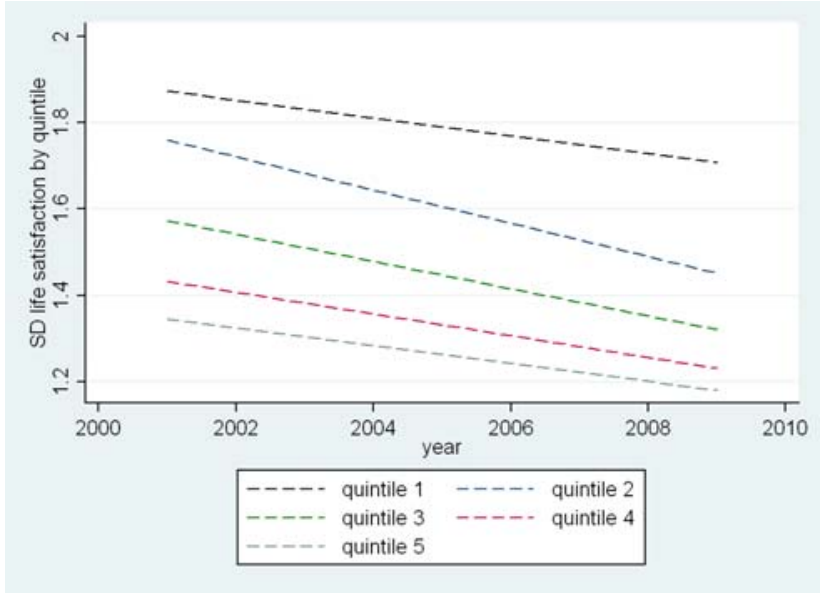

Figure 6.D Income inequality and happiness inequality: United States (GSS)
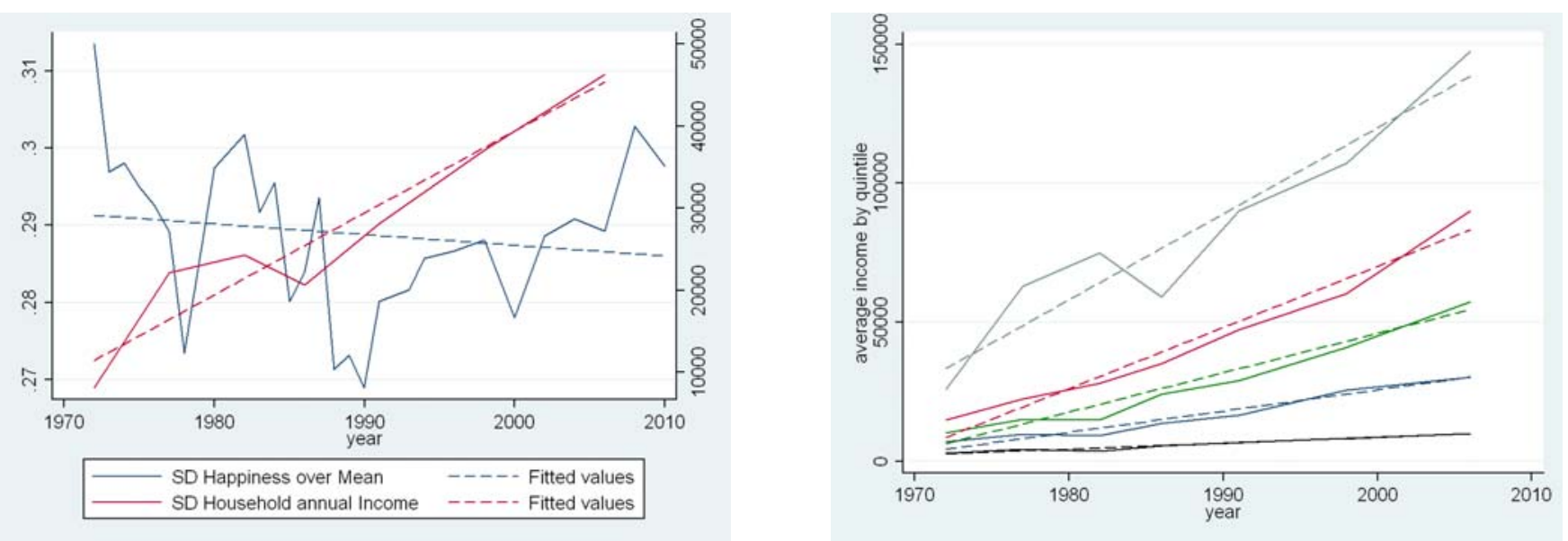

Legend: black (quintile 1), navy (quintile 2), green (quintile 3), cranberry (quintile 4), teal (quintile 5) 
GSS: 1972-1983

\section{Between}

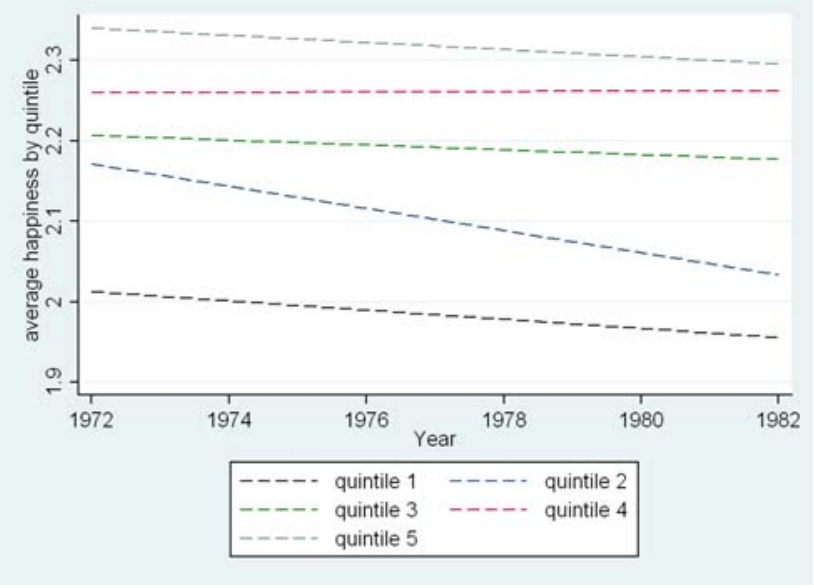

GSS: 1985-2006

\section{Between}

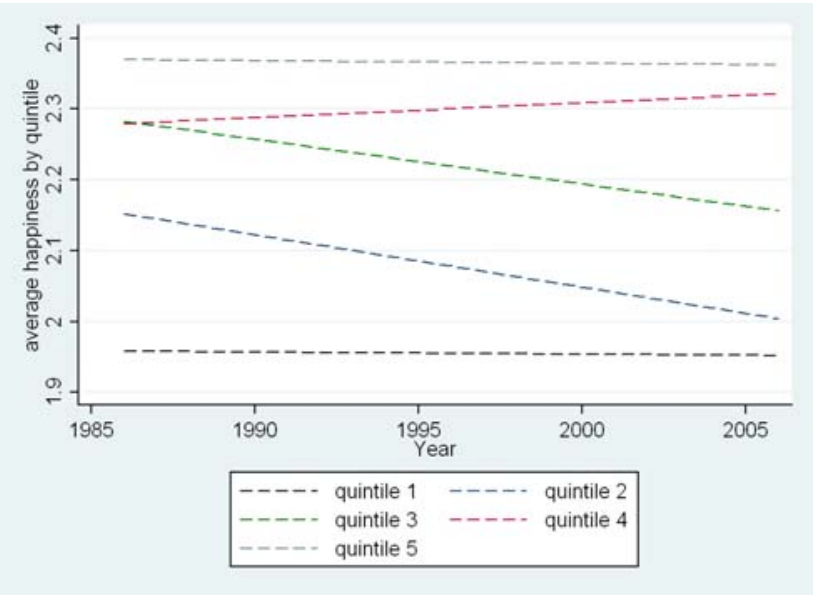

\section{Within}

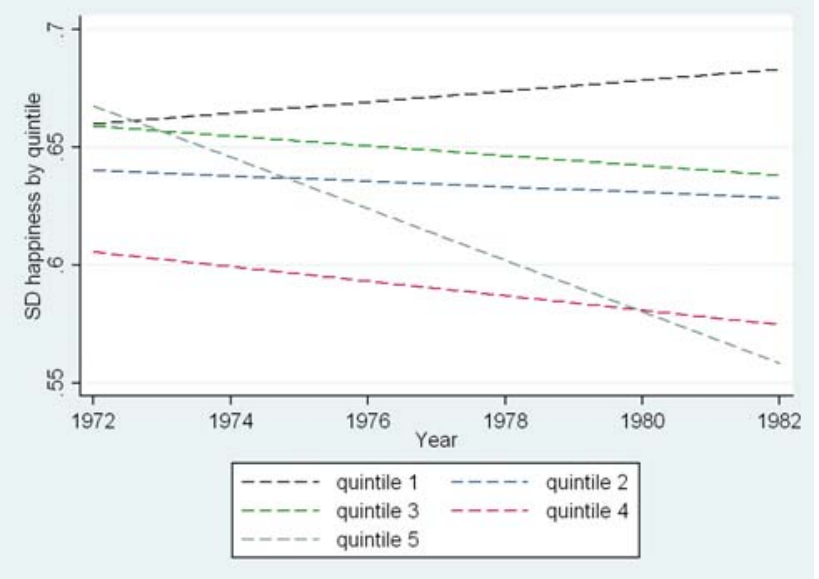

\section{Within}

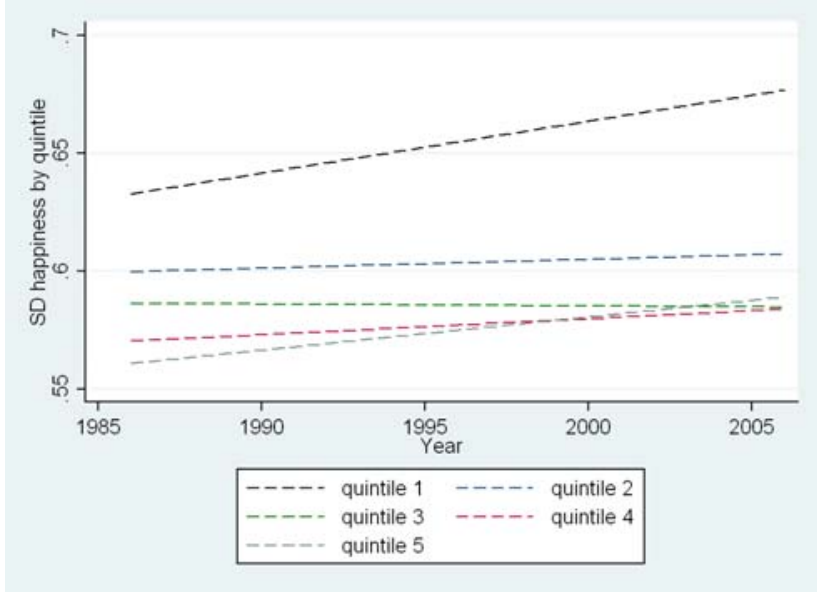


Figure 7.A Actual and simulated distribution of happiness: Great Britain (BHPS)

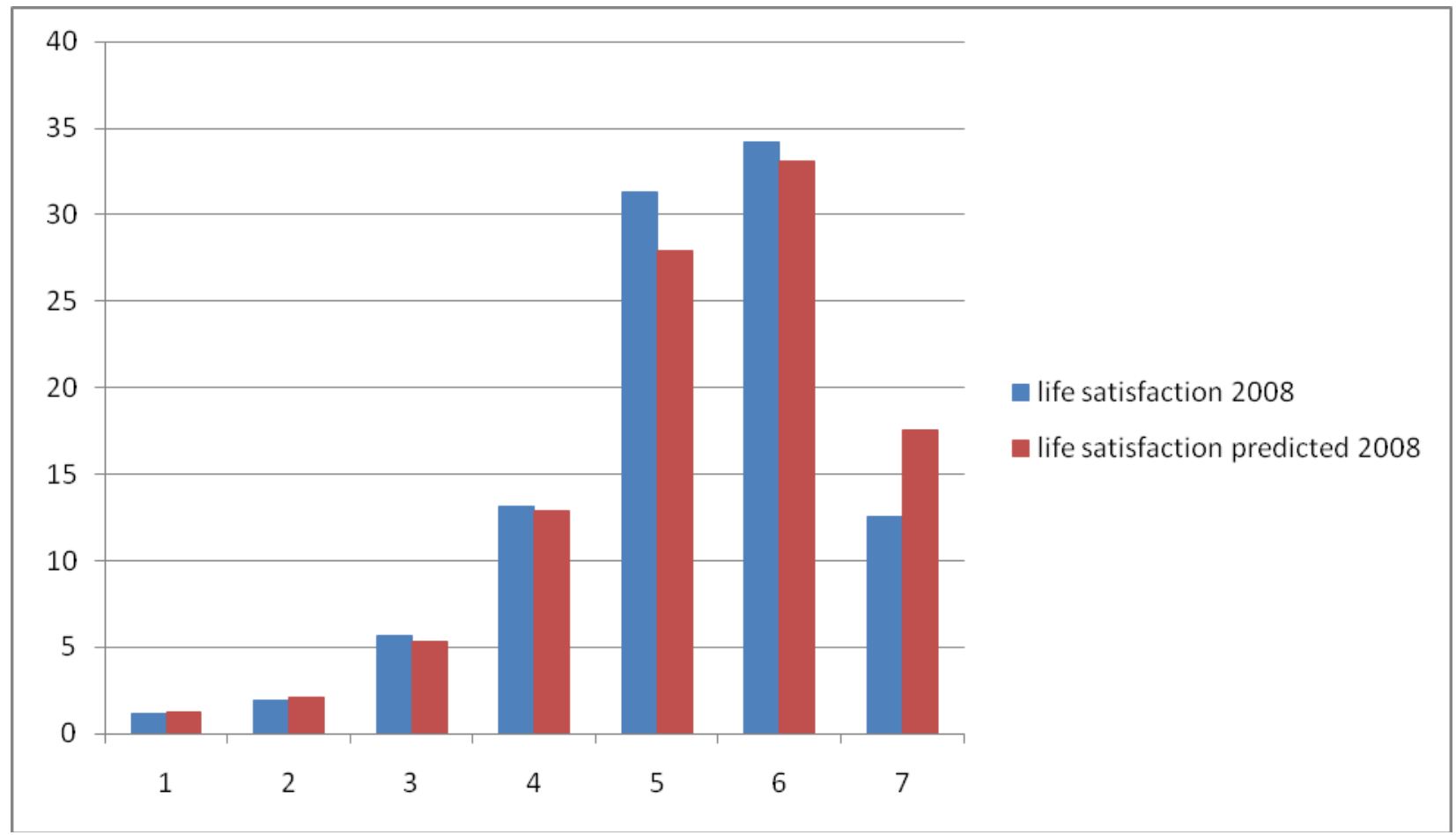

Estimation in 1996 of: Happiness $=a_{0}+a_{1}$ age $+a_{2}$ age ${ }^{2}+a_{3} \log$ income $+a_{4}$ female $+i$

Prediction of happiness in 2008 with the demographic composition of 2008 and the happiness function of 1996

\begin{tabular}{cccc}
\hline & Life satisfaction 1996 & $\begin{array}{c}\text { Life satisfaction } 2008 \\
\text { predicted }\end{array}$ & Life satisfaction 2008 \\
\hline Average & 5.23 & 5.47 & 5.24 \\
Standard deviation & 1.32 & 1.29 & 1.22 \\
\hline
\end{tabular}


Figure 7.B Actual and simulated distribution of happiness: Germany (SOEP)

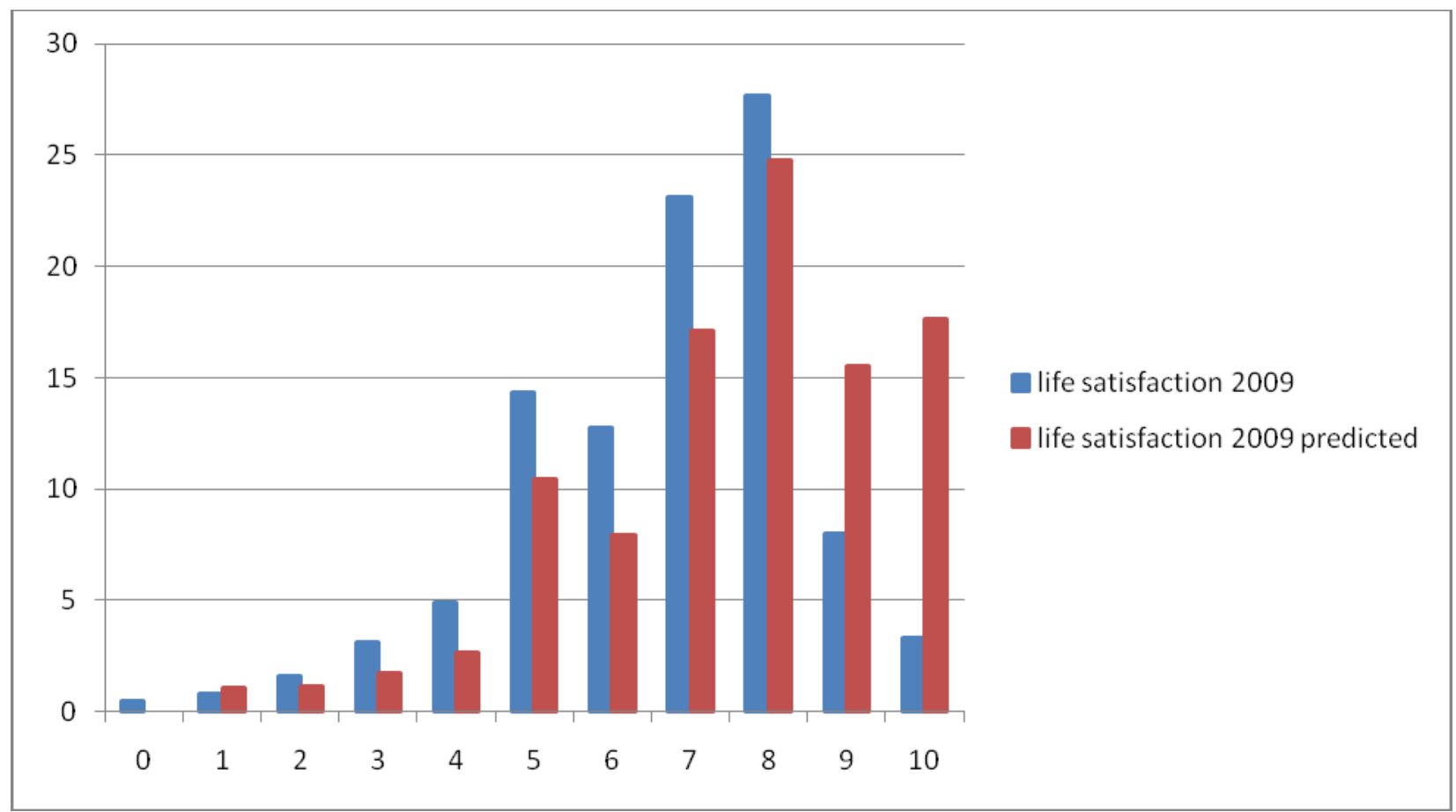

Prediction of happiness in 2009 with the happiness function estimated in 1984.

\begin{tabular}{cccc}
\hline & Life satisfaction 1984 & $\begin{array}{c}\text { Life satisfaction } 2009 \\
\text { predicted }\end{array}$ & Life satisfaction 2009 \\
\hline Average & 7.58 & 7.50 & 6.68 \\
Standard deviation & 1.97 & 2.00 & 1.83 \\
\hline
\end{tabular}


Figure 7.C Actual and simulated distribution of happiness: Australia (HILDA)

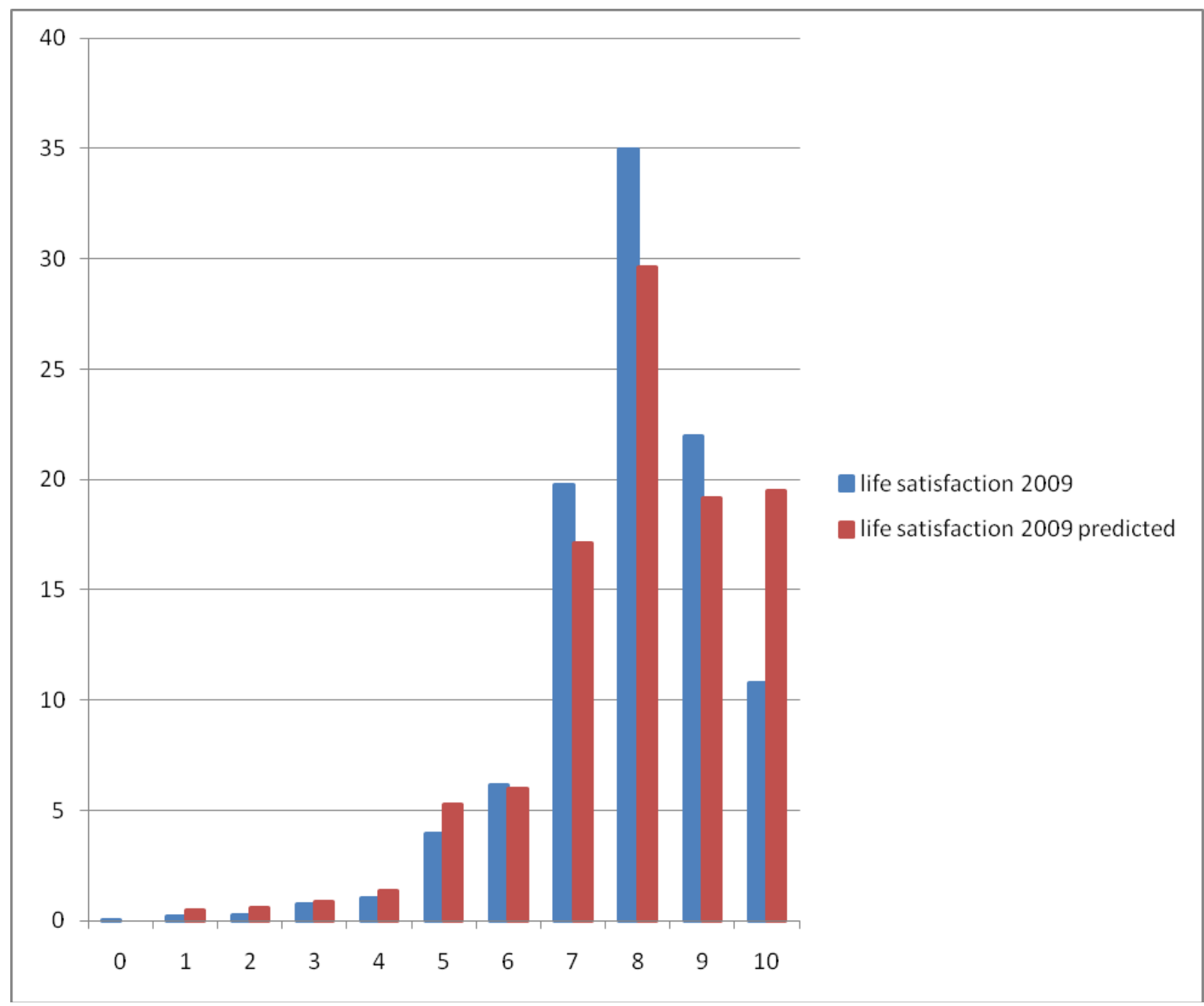

Prediction of happiness in 2009 with the happiness function estimated in 2001.

Life satisfaction 2001 Life satisfaction 2009 Life satisfaction 2009 predicted

\begin{tabular}{cccc}
\hline Average & 7.95 & 8.36 & 7.88 \\
Standard deviation & 1.66 & 1.69 & 1.42 \\
\hline
\end{tabular}


Figure 7.D Actual and simulated distribution of happiness: USA (GSS)

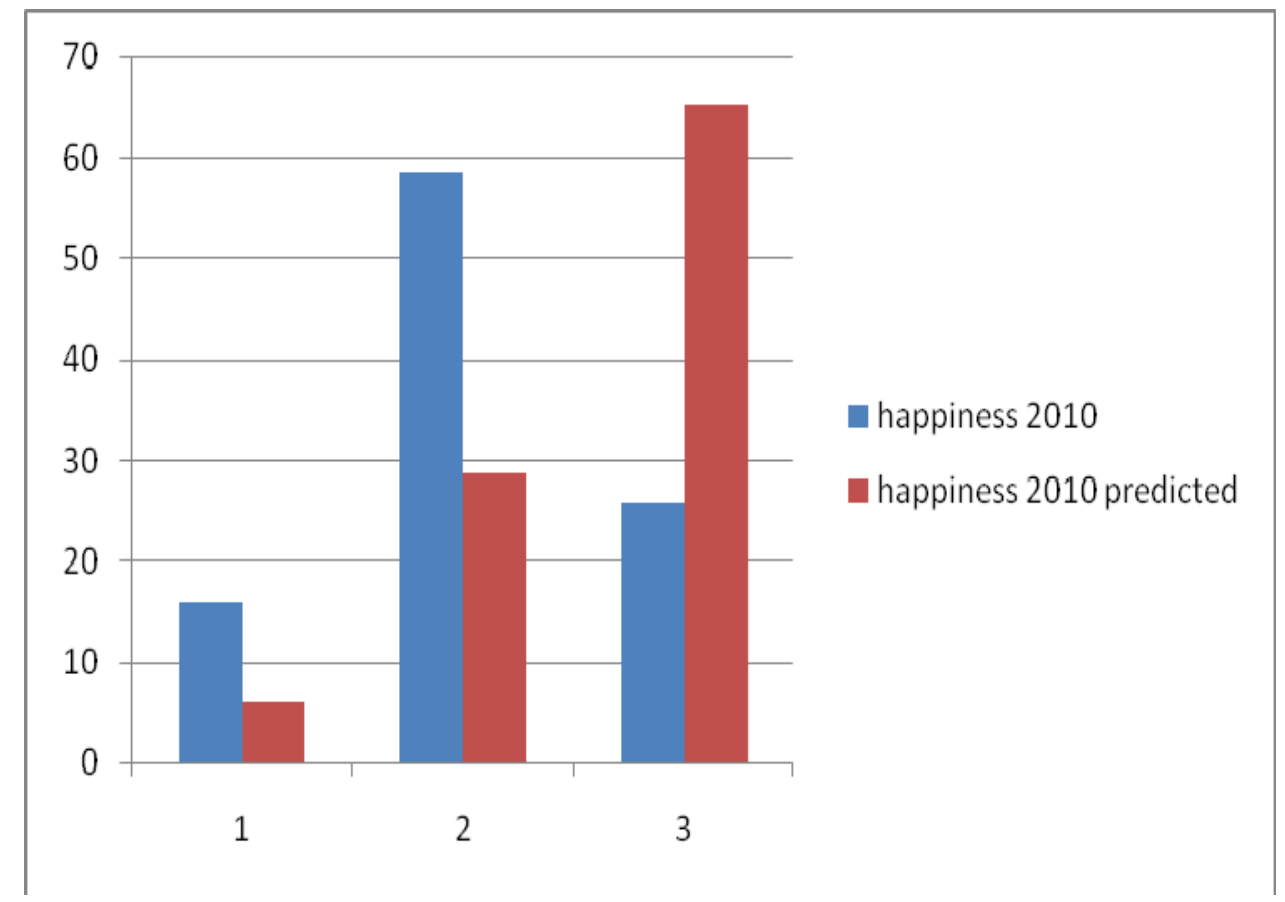

Prediction of happiness in 2010 with the happiness function estimated in 1972.

\begin{tabular}{cccc}
\hline & Happiness 1972 & $\begin{array}{c}\text { Happiness 2010 } \\
\text { predicted }\end{array}$ & Happiness 2010 \\
\hline Average & 2.14 & 2.58 & 2.09 \\
Standard deviation & 0.66 & 0.60 & 0.63 \\
\hline
\end{tabular}


Table 1.A World Values Survey

RIF estimates of the variance of life satisfaction across countries

\begin{tabular}{|c|c|c|c|c|c|c|}
\hline & (1) & (2) & (3) & (4) & (5) & (6) \\
\hline Ln GDP per capita & $\begin{array}{c}-0.528 * * * \\
(0.0159)\end{array}$ & $\begin{array}{c}-0.552 * * * \\
(0.0162)\end{array}$ & $\begin{array}{c}-0.687^{* * *} \\
(0.0214)\end{array}$ & $\begin{array}{c}-0.199 * * * \\
(0.0290)\end{array}$ & $\begin{array}{l}-0.0222 \\
(0.0300)\end{array}$ & $\begin{array}{c}-0.267 * * * \\
(0.0243)\end{array}$ \\
\hline Mean Ln Deviation & & $\begin{array}{c}7.739 * * * \\
(0.491)\end{array}$ & $\begin{array}{c}5.260 * * * \\
(0.552)\end{array}$ & $\begin{array}{c}6.530 * * * \\
(0.486)\end{array}$ & $\begin{array}{c}8.928 * * * \\
(0.490)\end{array}$ & $\begin{array}{c}9.360 * * * \\
(0.493)\end{array}$ \\
\hline Social Expenditure & & & $\begin{array}{c}0.00876 * * \\
(0.00357)\end{array}$ & & & \\
\hline Rule of law & & & & $\begin{array}{c}-0.929 * * * \\
(0.0386)\end{array}$ & & \\
\hline $\begin{array}{l}\text { Control of } \\
\text { corruption }\end{array}$ & & & & & $\begin{array}{c}-1.114^{* * *} \\
(0.0371)\end{array}$ & \\
\hline $\begin{array}{l}\text { Voice \& } \\
\text { accountability }\end{array}$ & & & & & & $\begin{array}{c}-1.104 * * * \\
(0.0383)\end{array}$ \\
\hline Observations & 126035 & 122681 & 86534 & 106628 & 106628 & 106628 \\
\hline R-squared & 0.041 & 0.043 & 0.048 & 0.054 & 0.057 & 0.056 \\
\hline
\end{tabular}

Other controls: Year fixed effects, age categories, gender, number of children, education, employment status, marital status. Standard errors are clustered at the country level. Weighted estimates. 


\section{RIF estimates of variance of life satisfaction over time}

\begin{tabular}{|c|c|c|c|}
\hline & (1) & (2) & (3) \\
\hline Ln GDP per capita & $\begin{array}{c}-0.849 * * * \\
(0.0756)\end{array}$ & $\begin{array}{c}-0.892 * * * \\
(0.0766)\end{array}$ & $\begin{array}{c}-0.892 * * * \\
(0.111)\end{array}$ \\
\hline Mean Ln Deviation & & $\begin{array}{c}4.265^{* * *} \\
(0.924)\end{array}$ & $\begin{array}{c}2.685 * * \\
(1.165)\end{array}$ \\
\hline Social expenditures & & & $\begin{array}{c}-0.0658 * * * \\
(0.0160)\end{array}$ \\
\hline Female & $\begin{array}{c}-0.0758^{*} \\
(0.0431)\end{array}$ & $\begin{array}{c}-0.0828 * \\
(0.0438)\end{array}$ & $\begin{array}{c}-0.0843^{*} \\
(0.0506)\end{array}$ \\
\hline Age $25-55$ & $\begin{array}{c}0.265^{* * *} \\
(0.0660)\end{array}$ & $\begin{array}{c}0.244^{* * *} \\
(0.0670)\end{array}$ & $\begin{array}{c}0.269 * * * \\
(0.0776)\end{array}$ \\
\hline Age $56-65$ & $\begin{array}{c}0.595 * * * \\
(0.0926)\end{array}$ & $\begin{array}{c}0.584 * * * \\
(0.0941)\end{array}$ & $\begin{array}{c}0.528 * * * \\
(0.108)\end{array}$ \\
\hline One child & $\begin{array}{l}-0.139 * \\
(0.0808)\end{array}$ & $\begin{array}{l}-0.154^{*} \\
(0.0819)\end{array}$ & $\begin{array}{l}-0.0398 \\
(0.0888)\end{array}$ \\
\hline Two children & $\begin{array}{l}-0.0825 \\
(0.0785)\end{array}$ & $\begin{array}{l}-0.0991 \\
(0.0796)\end{array}$ & $\begin{array}{c}-0.129 \\
(0.0871)\end{array}$ \\
\hline Three children & $\begin{array}{c}-0.118 \\
(0.0799)\end{array}$ & $\begin{array}{l}-0.140 * \\
(0.0810)\end{array}$ & $\begin{array}{c}0.0736 \\
(0.0900)\end{array}$ \\
\hline Married & $\begin{array}{c}0.0322 \\
(0.0776)\end{array}$ & $\begin{array}{c}0.0818 \\
(0.0787)\end{array}$ & $\begin{array}{c}0.0576 \\
(0.0850)\end{array}$ \\
\hline Divorced & $\begin{array}{c}0.787^{* * *} \\
(0.131)\end{array}$ & $\begin{array}{c}0.823 * * * \\
(0.133)\end{array}$ & $\begin{array}{c}0.815^{* * *} \\
(0.149)\end{array}$ \\
\hline Separated & $\begin{array}{c}1.016^{* * *} \\
(0.163)\end{array}$ & $\begin{array}{c}1.058^{* * *} \\
(0.166)\end{array}$ & $\begin{array}{c}1.300 * * * \\
(0.181)\end{array}$ \\
\hline Widowed & $\begin{array}{c}1.089 * * * \\
(0.135)\end{array}$ & $\begin{array}{c}1.157^{* * *} \\
(0.137)\end{array}$ & $\begin{array}{c}0.959 * * * \\
(0.157)\end{array}$ \\
\hline Not in labor force & $\begin{array}{c}0.223 * * * \\
(0.0587)\end{array}$ & $\begin{array}{c}0.220 * * * \\
(0.0597)\end{array}$ & $\begin{array}{c}0.293 * * * \\
(0.0687)\end{array}$ \\
\hline Student & $\begin{array}{c}0.0301 \\
(0.0877)\end{array}$ & $\begin{array}{c}0.0508 \\
(0.0889)\end{array}$ & $\begin{array}{c}0.344^{* * *} \\
(0.0990)\end{array}$ \\
\hline Unemployed & $\begin{array}{c}1.516 * * * \\
(0.0718)\end{array}$ & $\begin{array}{c}1.520 * * * \\
(0.0732)\end{array}$ & $\begin{array}{c}1.555^{* * *} \\
(0.0814)\end{array}$ \\
\hline Medium education & $\begin{array}{c}-0.757^{* * *} \\
(0.0496)\end{array}$ & $\begin{array}{c}-0.771^{* * *} \\
(0.0505)\end{array}$ & $\begin{array}{c}-0.974 * * * \\
(0.0576)\end{array}$ \\
\hline High education & $\begin{array}{c}-1.124 * * * \\
(0.0597) \\
(0.459)\end{array}$ & $\begin{array}{c}-1.126 * * * \\
(0.0607) \\
(45,538)\end{array}$ & $\begin{array}{c}-1.465 * * * \\
(0.0702) \\
(0.397)\end{array}$ \\
\hline Constant & $\begin{array}{c}13.19 * * * \\
(0.776)\end{array}$ & $\begin{array}{c}13.85 \\
(45,538)\end{array}$ & $\begin{array}{c}13.22^{* * *} \\
(0.799)\end{array}$ \\
\hline Observations & 126035 & 122681 & 86534 \\
\hline R-squared & 0.073 & 0.073 & 0.064 \\
\hline
\end{tabular}

